\title{
58. PALEOMAGNETISM AND SOME MAGNETIC PROPERTIES OF BASALTS FROM THE BERMUDA TRIANGLE
}

\author{
Shaul Levi, School of Oceanography, Oregon State University, Corvallis, Oregon
}

\section{INTRODUCTION}

Largely through the efforts of the Deep Sea Drilling Project (DSDP), information about the magnetic properties of the igneous oceanic crust has been accumulating rapidly during the past decade. One of the more significant facts which has emerged is that these rocks often have very different magnetic properties from those inferred from studies of magnetic anomalies near spreading centers (Talwani et al., 1971; Atwater and Mudie, 1973; and Klitgord et al., 1975), or from rock magnetic studies of oceanic extrusives dredged near spreading centers (Irving et al., 1970; Carmichael, 1970; Prévot et al., 1976; and Johnson and Atwater, 1977). Although Lowrie (1977) noted that the paleoinclinations of basalts from early DSDP sites are consistent with the paleolatitudes of the sites (correlation coefficient $=0.912$ ), the results of many studies show that the stable inclinations are often anomalous (usually shallow) relative to those expected from a geocentric axial dipole field (Cox and Doell, 1962; Brooke et al., 1970; Lowrie and Opdyke, 1972, 1973; Ade-Hall et al., 1973; and Ryall and Hall, 1977). Sometimes reversals are observed in the vertical column of a single hole (e.g., Faller et al., 1979 and Johnson and Merrill, 1978). Furthermore, the relatively low intensities of remanent magnetization $\left(J_{N R M}\right)$ which are usually observed imply that a magnetic layer several kilometers thick is required to produce the observed anomalies (Lowrie, 1973; Scientific Party, 1975; and Harrison, 1976). For these reasons the purpose of Legs 51, 52, and 53 was to attempt the deepest possible penetration into oceanic Layer 2. A total of 1128.6 meters of igneous rocks was cored at four closely spaced sites in the western Atlantic Ocean at $25.0^{\circ} \mathrm{N}$ and $69.0^{\circ} \mathrm{W}$ (Hole 417A [209.0 m], 417D [365.5 $\mathrm{m}$ ], 418A [544.0], and 418B [10.1 m]). The maximum separation between any two holes is less than 5 kilometers. The drill sites were located in reversely magnetized anomaly $M 0$, whose inferred age is approximately 108 m.y.

This report is based on magnetic measurements of 399 igneous-rock specimens from Holes 417D and 418A and constitutes the shipboard and shore-based paleomagnetic studies of Leg 52. Data for the individual samples are listed in an accompanying chapter (Levi et al., this volume). Here, except where inappropriate, the magnetic data are presented as averages over 10-meter core intervals. This approach has the advantage of focusing greater attention on the gross magnetic properties of each hole, which is particularly important for understanding the nature of the source layer of the magnetic anomalies. Most data used in this report are contained in Table 1, where each datum corresponds to a particular 10-meter interval and represents the arithmetic mean associated with the samples of that depth interval. The uncertainties represent one standard deviation; the number in parentheses to the right of each datum denotes the number of samples used in obtaining the mean.

\section{RESULTS AND DISCUSSION}

\section{Magnetic Properties: Intensity, Susceptibility, and Stability of Magnetization}

Downhole variations of $J_{N R M}$ (intensity of remanent magnetization), $\chi$ (low-field susceptibility), and $Q$ (Königsberger ratio) are shown in Figures 1 and 2. Downhole variations of the MDF (median demagnetizating field) are plotted on the right-hand side of Figures 3 and 4 . The downhole profiles of $J_{N R M}$ and $Q$ are similar to one another in both Holes 417D and $418 \mathrm{~A}$. The similarity might be partly fortuitous, because the action of the present field on the predominantly reversed primary remanence results in preferentially lowering the net remanence of specimens with greatest induced magnetic moment, hence lowering $Q$. However, the essentially positive correlation between $J_{N R M}$ and $Q$ persists even for the normally magnetized upper 178 meters of Hole $418 \mathrm{~A}$. Although $\chi$ varies more gently, higher $\chi$ values are frequently associated with lower values of $Q$ (and $J_{\text {NRM }}$ ) and lower $\chi$ values with higher values of $Q$ (and $J_{N R M}$ ); exceptions do however, exist. Similar behavior of $\chi, Q$, and $M D F$ was observed at DSDP Site 163 (Marshall, 1978).

The lithologic identifications used in this report to distinguish units such as massive flows, pillow basalts, breccia, and dikes follow exactly the core descriptions of the shipboard petrologists of the respective Legs. Contact relationships and morphology of the cooling surfaces and grain size gradations were among the important factors used to distinguish between the lithologic units.

In Hole $417 \mathrm{D}$, there is a marked distinction between the magnetic properties ( $J_{N R M}, \chi, Q$, and MDF) of the massive flow units and the pillow basalts (Table 2). The massive flow units usually have lower $J_{N R M}, Q$, and MDF and higher $\chi$ values, whereas the pillow basalts more often exhibit lower $\chi$ and higher $J_{N R M}, Q$, and MDF values. Although these trends are unmistakable in Hole 417D, considerable scatter exists within each lithology, and there is no such straightforward distinction for the massive flows and pillow basalts of Hole 418A.

The distinction in the magnetic properties between the pillow basalts and massive flows of Hole 417D, and the lack of distinction between the pillow basalts and massive flows of Hole 418A is in good agreement with preliminary particle-size measurements of the titanomagnetite grains. Many of the conspicuous grains in the massive flows of Hole 417D are between 50 and $200 \mu \mathrm{m}$, whereas titanomagnetite grains larger than $10 \mu \mathrm{m}$ are rare in the pillow basalts. On the other hand, no significant difference in the titanomagnetite grain sizes was observed between massive 
TABLE 1A

Magnetic Properties of Hole 417D (averages of $10-\mathrm{m}$ intervals)

\begin{tabular}{|c|c|c|c|c|c|c|}
\hline $\begin{array}{l}\text { Depth Sub-a } \\
\text { Bottom (m) }\end{array}$ & Rock Type ${ }^{b}$ & $I_{S T A B L E}^{\mathrm{c}}$ & $J_{N R M}^{\mathrm{d}}$ & $x^{e}$ & $Q^{\mathrm{f}}$ & $\mathrm{MDF}^{\mathrm{g}}$ \\
\hline $345-355$ & $\mathrm{p}$ & $-66 \pm 5(2)$ & $8.90 \pm 4.82(2)$ & $1.77 \pm .36(2)$ & $11.8 \pm 8.3(2)$ & $154 \pm 60(2)$ \\
\hline $355-365$ & $\mathrm{p}$ & $-67 \pm 1(2)$ & $12.0 \pm 2.9(2)$ & $1.82 \pm .13(2)$ & $14.6 \pm 4.6(2)$ & $134 \pm 11(2)$ \\
\hline $365-375$ & $\mathrm{p}$ & $-75 \pm 1(4)$ & $9.71 \pm 3.16(4)$ & $1.11 \pm .59(4)$ & $23.5 \pm 12.2(4)$ & $210 \pm 141(4)$ \\
\hline $375-385$ & $\mathrm{p}$ & $-72 \pm 1(2)$ & $9.48 \pm 3.71(2)$ & $0.94 \pm .24(2)$ & $21.5 \pm 3.1(2)$ & $204 \pm 1(2)$ \\
\hline $385-395$ & $\mathrm{p}$ & $-67 \pm 4(3)$ & $6.80 \pm 1.19(3)$ & $1.54 \pm .04(3)$ & $9.6 \pm 1.9(3)$ & $168 \pm 120(3)$ \\
\hline $395-405$ & $\mathrm{p}$ & $-70 \pm 4(4)$ & $7.94 \pm 1.81(4)$ & $1.56 \pm .66(4)$ & $14.9 \pm 12.3(4)$ & $109 \pm 19(4)$ \\
\hline $405-415$ & $\mathrm{p}(1) / \mathrm{m}(1)$ & $-66 \pm 5(2)$ & $7.32 \pm 4.36(2)$ & $1.90 \pm 1.21(2)$ & $12.6 \pm 13.0(2)$ & $118 \pm 115(2)$ \\
\hline $415-425$ & $\mathrm{~m}$ & $-69 \pm 3(2)$ & $13.9 \pm 18.6(3)$ & $2.30 \pm .30(3)$ & $14.9 \pm 21.0(3)$ & $141 \pm 123(3)$ \\
\hline $425-435$ & $\mathrm{~m}$ & $-59 \pm 1(2)$ & $2.96 \pm 2.72$ & $2.31 \pm .30(3)$ & $2.8 \pm 2.7(3)$ & $117 \pm 79(3)$ \\
\hline $435-445$ & $\mathrm{p}$ & $-62 \pm 4(4)$ & $8.55 \pm 4.14(3)$ & $2.23 \pm .32(4)$ & $9.3 \pm 6.4(3)$ & $108 \pm 34(3)$ \\
\hline $445-455$ & $\mathrm{p}$ & $-70 \pm 6(5)$ & $15.6 \pm 8.3(5)$ & $1.57 \pm .53(5)$ & $22.8 \pm 11.2(5)$ & $159 \pm 58(5)$ \\
\hline $455-465$ & $\mathrm{p}$ & $-69 \pm 4(5)$ & $15.3 \pm 4.8(5)$ & $1.86 \pm .49(5)$ & $19.3 \pm 9.1(5)$ & $138 \pm 28(5)$ \\
\hline $465-475$ & $\mathrm{p}$ & $-70 \pm 10(4)$ & $11.9 \pm 7.6(4)$ & $2.18 \pm 1.09(4)$ & $16.3 \pm 13.6(4)$ & $111 \pm 32(4)$ \\
\hline $475-485$ & $\mathrm{p}$ & $-65 \pm 9(5)$ & $10.7 \pm 1.8(5)$ & $1.79 \pm .75(5)$ & $15.9 \pm 8.5(5)$ & $134 \pm 45(5)$ \\
\hline $485-490$ & $\mathrm{p}$ & $-60 \pm 7(4)$ & $5.38 \pm 6.03(4)$ & $1.65 \pm .22(4)$ & $7.5 \pm 8.3(4)$ & $114 \pm 25(4)$ \\
\hline $490-495$ & $\mathrm{p}$ & $-22 \pm 7(3)$ & $3.60 \pm 1.23(3)$ & $2.46 \pm .08(3)$ & $3.1 \pm 1.0(3)$ & $95 \pm 33(3)$ \\
\hline $495-505$ & $\mathrm{p}(1) / \mathrm{m}(1)$ & $-26 \pm 3(2)$ & $0.33 \pm 0.16(2)$ & $2.61 \pm .07(2)$ & $0.3 \pm 0.14(2)$ & $31 \pm 13(2)$ \\
\hline $505-515$ & p & $-27 \pm 1(3)$ & $3.10 \pm 2.87(3)$ & $2.60 \pm .25(3)$ & $2.8 \pm 2.8(3)$ & $111 \pm 67(3)$ \\
\hline $515-525$ & - & - & - & - & - & - \\
\hline $525-530$ & - & - & - & - & - & - \\
\hline $530-540$ & $\mathrm{~m}$ & $-19 \pm 6(4)$ & $2.91 \pm 0.99(6)$ & $3.10 \pm .30(8)$ & $2.0 \pm 0.7(6)$ & $80 \pm 41(5)$ \\
\hline $540-550$ & $\mathrm{~m}$ & $-27 \pm 4(5)$ & $2.32 \pm 1.73(10)$ & $3.00 \pm .42(9)$ & $1.9 \pm 1.8(9)$ & $132 \pm 72(8)$ \\
\hline $550-560$ & $\mathrm{~m}$ & $-14 \pm 6(2)$ & $4.33 \quad$ (1) & $2.83 \pm .10(2)$ & 3.2 (1) & 28 (1) \\
\hline $560-570$ & $\mathrm{~m}(4) / \mathrm{p}(7)$ & $-15 \pm 6(9)$ & $9.47 \pm 5.22(10)$ & $3.01 \pm .29(11)$ & $6.8 \pm .3(10)$ & $97 \pm 30(9)$ \\
\hline $570-580$ & $\mathrm{p}$ & $-19 \pm 3(3)$ & $25.5 \pm 7.7(3)$ & $2.36 \pm .44(3)$ & $24.4 \pm 8.8(3)$ & $126 \pm 47(3)$ \\
\hline $580-590$ & $\mathrm{p}$ & $-19 \pm 3(8)$ & $22.2 \pm 7.3(8)$ & $2.45 \pm .31(9)$ & $19.6 \pm 7.0(8)$ & $101 \pm 29(8)$ \\
\hline $590-600$ & $\mathrm{p}$ & $-19 \pm 7(3)$ & $16.9 \pm 4.4(3)$ & $2.88 \pm .41(4)$ & $12.0 \pm 3.6(3)$ & $91 \pm 34(3)$ \\
\hline $\begin{array}{l}600-606.5 \\
606.5-610\end{array}$ & $\underset{\text { breccia }}{\mathrm{p}}$ & $\begin{array}{l}-22 \pm 9(2) \\
-25 \pm 43(4)\end{array}$ & $14.2 \pm 7.0(6)$ & $2.66 \pm .29(6)$ & $11.6 \pm 5.7(6)$ & $107 \pm 17(6)$ \\
\hline $610-620$ & breccia & $-37 \pm 75(3)$ & $13.8 \pm 5.6(3)$ & $2.04 \pm .49(3)$ & $14.8 \pm 4.8(3)$ & $139 \pm 23(3)$ \\
\hline $620-630$ & breccia & $18 \pm 72(4)$ & $4.19 \pm 5.47(4)$ & $2.06 \pm 1.24(4)$ & $4.3 \pm 4.2(4)$ & $86 \pm 13(4)$ \\
\hline $630-640$ & breccia & $29 \pm 40(10)$ & $5.91 \pm 5.0(12)$ & $2.46 \pm .93(13)$ & $6.4 \pm 7.1(12)$ & $88 \pm 68(10)$ \\
\hline $640-650$ & $\mathrm{p}$ & $-35 \pm 3(16)$ & $5.98 \pm 3.34(16)$ & $1.45 \pm .72(16)$ & $12.1 \pm 9.0(16)$ & $142 \pm 96(16)$ \\
\hline $650-660$ & p & $-34 \pm 6(7)$ & $11.8 \pm 6.6(5)$ & $2.12 \pm .66(7)$ & $13.8 \pm 8.5(5)$ & $102 \pm 55(5)$ \\
\hline $660-670$ & $\mathrm{p}(3) / \mathrm{m}(2)$ & $-45 \pm 4(5)$ & $11.5 \pm 2.0(5)$ & $2.09 \pm .61(5)$ & $13.3 \pm 5.6(5)$ & $102 \pm 30(5)$ \\
\hline $670-680$ & $\mathrm{~m}(5) / \mathrm{p}(1)$ & $-49 \pm 7(6)$ & $5.26 \pm 1.13(4)$ & $2.71 \pm .24(6)$ & $4.2 \pm .9(4)$ & $65 \pm 25(4)$ \\
\hline $680-690$ & $\mathrm{p}(5) / \mathrm{m}(2)$ & $-55 \pm 12(7)$ & $6.05 \pm 5.34(5)$ & $2.06 \pm .73(7)$ & $8.2 \pm 9.5(5)$ & $109 \pm 54(5)$ \\
\hline $690-700$ & $\mathrm{~m}$ & $-54 \pm 9(4)$ & $3.61 \pm 1.73(4)$ & $3.04 \pm .45(6)$ & $2.6 \pm 1.4(4)$ & $32 \pm 12(4)$ \\
\hline $697-701$ & dike & $-64 \pm 2(4)$ & $17.0 \pm 2.7(4)$ & $2.29 \pm .22(3)$ & $16.1 \pm 1.7(3)$ & 172 (1) \\
\hline $700-710$ & $\mathrm{~m}$ & $-50 \pm 12(2)$ & $3.29 \pm 2.1(5)$ & $3.05 \pm .32(8)$ & $2.2 \pm 1.3(5)$ & $27 \pm 6(3)$ \\
\hline \multicolumn{7}{|c|}{ 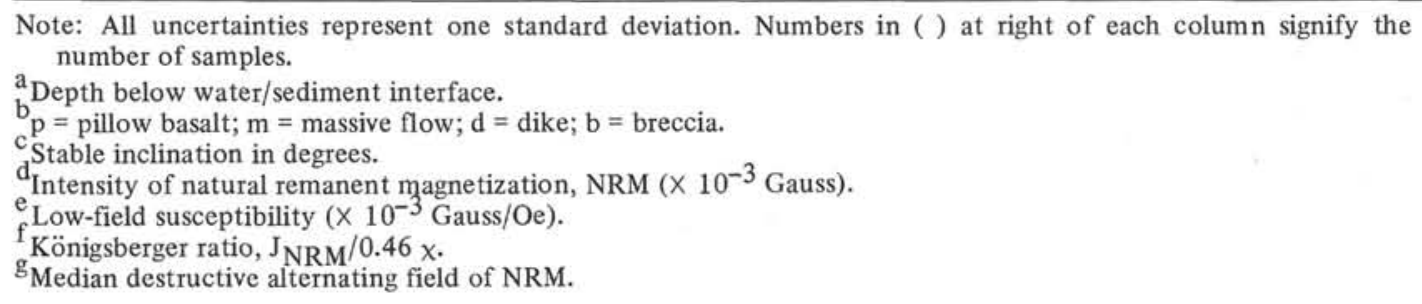 } \\
\hline
\end{tabular}

flow units and pillow basalts of the upper 178-meter section of Hole 418A, where the grain sizes are typically less than $20 \mu \mathrm{m}$. The titanomagnetites of the lower 200 -meter section of Hole 418A (excluding the bottom $10 \mathrm{~m}$ for which we have no data) are of larger grain sizes, often between 20 and $150 \mu \mathrm{m}$, and the massive flows appear to have somewhat coarser titanomagnetite grains. Although these observations are clearly biased toward the larger particles, we assume they are accurate indicators of the distributions which they represent.

The distinction in the magnetic properties between the massive flows and pillow basalts of Hole 417D and the gross trends in the magnetic property profiles in Hole 418A can be readily understood in terms of variations of the aver- age particle size of the magnetic minerals. Assuming constant composition and density of the magnetic constituent neglecting intensity fluctuations of the geomagnetic field and ignoring effects of fluctuations in the oxidation state relatively higher primary TRM (thermal remanent magnetization) and greater stability (MDF) are expected for those samples (with smaller particle sizes) whose remanence is predominantly in single domain (SD) and pseudosingle domain (PSD) particles than for samples whose remanence is predominantly in multidomain (MD) particles (e.g., Levi and Merrill, 1978). Similarly, because relatively lower energy barriers are associated with domain wall movement of MD remanence than with domain rotation of SD particles, relatively higher values for $\chi$ are expected for MD than 
TABLE 1B

Magnetic Properties of Hole 418A (averages of 10-m intervals)

\begin{tabular}{|c|c|c|c|c|c|c|}
\hline $\begin{array}{l}\text { Depth Sub-a } \\
\text { Bottom }(m)\end{array}$ & Rock Type ${ }^{b}$ & $I_{S T A B L E}^{\mathrm{C}}$ & $J_{N R M}^{\mathrm{d}}$ & $x^{e}$ & $Q^{\mathrm{f}}$ & $\mathrm{MDF}^{\mathrm{g}}$ \\
\hline $320-330$ & $\mathrm{p}(3) / \mathrm{m}(1)$ & $20 \pm 7(4)$ & $\pm 12(4)$ & $1.67 \pm .26(4)$ & $23.3 \pm 16(4)$ & $98 \pm 26(4)$ \\
\hline $330-340$ & $\mathrm{~m}$ & $18 \pm 4(6)$ & $\pm 12(8)$ & $1.82 \pm .32(7)$ & $20.0 \pm 23(7)$ & $94 \pm 37(7)$ \\
\hline $340-350$ & $\mathrm{~m}$ & $25 \pm 2(5)$ & $\pm 7(5)$ & $1.89 \pm .35(5)$ & $12.6 \pm 8(5)$ & $99 \pm 26(5)$ \\
\hline $350-360$ & $\mathrm{~m}$ & $28 \pm 3(5)$ & $\pm 12(5)$ & $1.50 \pm .69(5)$ & $42.5 \pm 52(5)$ & $125 \pm 65(5)$ \\
\hline $360-370$ & $\mathrm{~m}$ & $25 \pm 3(11)$ & $\pm 17(11)$ & $1.50 \pm .58(11)$ & $45.5 \pm 50(11)$ & $124 \pm 46(11)$ \\
\hline $370-380$ & $\mathrm{~m}(2) / \mathrm{p}(3)$ & $30 \pm 2(5)$ & $\pm 3(5)$ & $1.42 \pm .40(5)$ & $26.6 \pm 16(5)$ & $144 \pm 61(5)$ \\
\hline $380-390$ & $\mathrm{p}(6) / \mathrm{m}(5)$ & $31 \pm 5(11)$ & $\pm 4(11)$ & $1.81 \pm .28(11)$ & $12.7 \pm 5(11)$ & $100 \pm 24(11)$ \\
\hline $390-400$ & $\mathrm{p}(4) / \mathrm{b}(1)$ & $31 \pm 7(4)$ & $\pm 5(5)$ & $1.50 \pm .73(5)$ & $19.2 \pm 6(5)$ & $143 \pm 33(5)$ \\
\hline $400-410$ & $\mathrm{p}(4) / \mathrm{b}(4)$ & $24 \pm 1(4)$ & $\pm 8(8)$ & $1.28 \pm .81(8)$ & $14.9 \pm 9(8)$ & $121 \pm 47(8)$ \\
\hline $410-420$ & p & $20 \pm 5(7)$ & $17.3 \pm 7(7)$ & $1.93 \pm .17(7)$ & $19.9 \pm 9(7)$ & $119 \pm 29(7)$ \\
\hline $420-430$ & $\mathrm{p}(2) / \mathrm{b}(3)$ & $35 \pm 0(2)$ & $9.56 \pm 9(5)$ & $0.85 \pm .80(5)$ & $1.83 \pm 11(5)$ & $224 \pm 85(5)$ \\
\hline $430-440$ & - & - & - & - & - & - \\
\hline $440-450$ & $\mathrm{p}$ & $21 \pm 5(6)$ & $10.2 \pm 1(6)$ & $2.01 \pm .24(6)$ & $11.2 \pm 2(6)$ & $100 \pm 31(6)$ \\
\hline $450-460$ & $\mathrm{p}(4) / \mathrm{b}(3)$ & $19 \pm 3(3)$ & $7.18 \pm 4(7)$ & $1.70 \pm .68(6)$ & $8.9 \pm 4(6)$ & $117 \pm 36(4)$ \\
\hline $460-470$ & $\mathrm{p}$ & $24 \pm 4(6)$ & $6.87 \pm 4(6)$ & $1.21 \pm .51(6)$ & $12.5 \pm 4(6)$ & $154 \pm 44(6)$ \\
\hline $470-480$ & $\mathrm{p}$ & $22 \pm 4(7)$ & $10.1 \pm 8(7)$ & $1.22 \pm .49(7)$ & $16.3 \pm 9(7)$ & $157 \pm 35(7)$ \\
\hline $480-490$ & $\mathrm{p}$ & $25 \pm 2(4)$ & $\pm 3(4)$ & $1.77 \pm .24(4)$ & $15.6 \pm 6(4)$ & $128 \pm 35(4)$ \\
\hline $490-498$ & $\mathrm{p}$ & $25 \pm 3(4)$ & $20.2 \pm 11(4)$ & $2.10 \pm .22(3)$ & $22.6 \pm 12(3)$ & $99 \pm 8(4)$ \\
\hline $498-510$ & breccia & $1 \pm 52(13)$ & $6.23 \pm 6(14)$ & $0.95 \pm .70(13)$ & $15.4 \pm 10(13)$ & $182 \pm 51(14)$ \\
\hline $510-520$ & $\mathrm{p}$ & $-33 \pm 3(7)$ & $14.0 \pm 4(8)$ & $0.88 \pm .27(7)$ & $37.4 \pm 11(7)$ & $221 \pm 59(7)$ \\
\hline $520-530$ & $\mathrm{p}$ & $-30 \pm 6(7)$ & $\pm 5(10)$ & $1.17 \pm .42(7)$ & $39.3 \pm 19(7)$ & $162 \pm 83(7)$ \\
\hline $530-540$ & $\mathrm{p}$ & $-35 \pm 4(5)$ & $24.2 \pm 3(5)$ & $0.79 \pm .26(5)$ & $76.5 \pm 42(5)$ & $229 \pm 38(5)$ \\
\hline $540-550$ & $\mathrm{p}$ & $-33 \pm 3(5)$ & $\pm 8(5)$ & $0.49 \pm .16(5)$ & $109.8 \pm 40(5)$ & $359 \pm 31(5)$ \\
\hline $550-560$ & $\mathrm{p}$ & $-32 \pm 3(4)$ & $\pm 6(4)$ & $1.07 \pm .25(3)$ & $48.2 \pm 26(3)$ & $196 \pm 53(4)$ \\
\hline $560-570$ & $\mathrm{p}$ & $-27 \pm 2(6)$ & $22.6 \pm 7(6)$ & $0.89 \pm .26(4)$ & $60.6 \pm 22(4)$ & $241 \pm 85(5)$ \\
\hline $570-580$ & $\mathrm{p}$ & $-25 \quad(1)$ & $19.5 \quad(1)$ & $0.46 \quad(1)$ & $92.2 \quad(1)$ & $381 \quad(1)$ \\
\hline $580-590$ & $\mathrm{p}$ & $-23 \quad(1)$ & 15.9 & $0.46 \quad(1)$ & $75.1 \quad$ (1) & $366 \quad(1)$ \\
\hline $590-600$ & $\mathrm{p}$ & -17 (1) & $20.9 \quad$ (1) & $1.67 \quad(1)$ & 27.2 (1) & 117 (1) \\
\hline $600-610$ & $\mathrm{p}$ & $-24 \pm 0(2)$ & $19.2 \pm 2(2)$ & $1.89 \pm .01(2)$ & $22.2 \pm 2(2)$ & $94 \pm 4(2)$ \\
\hline $610-620$ & - & - & - & - & - & - \\
\hline $620-630$ & $\mathrm{p}$ & $-31 \quad(1)$ & $28.5 \quad$ (1) & $2.96 \quad(1)$ & 20.9 (1) & 92 (1) \\
\hline $630-640$ & $\mathrm{~m}$ & $-48 \quad(1)$ & $12.2 \quad(1)$ & 2.52 & 10.5 & 78 (1) \\
\hline $640-650$ & - & - & - & - & - & - \\
\hline $650-660$ & - & - & - & - & - & - \\
\hline $660-670$ & $\mathrm{p}$ & $-23 \pm 2(3)$ & $14.9 \pm 1(3)$ & $3.28 \pm .94(3)$ & $10.6 \pm 4(3)$ & $90 \pm 19(3)$ \\
\hline $670-680$ & $\mathrm{~m}$ & $-18 \quad(1)$ & $11.6 \quad(1)$ & $2.58 \quad(1)$ & $9.8 \quad(1)$ & $106 \quad(1)$ \\
\hline $680-690$ & $\mathrm{p}$ & $-26 \pm 6(2)$ & $11.4 \pm 8(2)$ & $4.17 \pm .40(2)$ & $6.2 \pm 5(2)$ & $75 \pm 18(2)$ \\
\hline $690-700$ & $\mathrm{p}$ & $-34 \pm 6(4)$ & $12.4 \pm 11(4)$ & $3.32 \pm .91(4)$ & $10.0 \pm 10(4)$ & $118 \pm 38(4)$ \\
\hline $700-710$ & $\mathrm{p}$ & $-39 \pm 11(3)$ & $8.08 \pm 5(3)$ & $2.15 \pm 1.5(3)$ & $10.0 \pm 4(3)$ & $191 \pm 148(3)$ \\
\hline $710-720$ & $\mathrm{p}$ & -68 (1) & $8.58 \quad$ (1) & 3.23 (1) & $5.8 \quad(1)$ & 85 (1) \\
\hline $720-730$ & $\mathrm{p}$ & $-46 \pm 10(3)$ & $13.3 \pm 3(3)$ & $2.64 \pm .67(3)$ & $12.0 \pm 6(3)$ & $104 \pm 18(3)$ \\
\hline $730-740$ & $\mathrm{p}$ & $-65 \pm 6(3)$ & $7.18 \pm 5(3)$ & $2.38 \pm .29(3)$ & $6.8 \pm 5(3)$ & $93 \pm 10(3)$ \\
\hline $740-750$ & $\mathrm{p}$ & $-56 \pm 14(4)$ & $4.49 \pm 4(4)$ & $3.06 \pm .36(4)$ & $3.4 \pm 3(4)$ & $90 \pm 3(4)$ \\
\hline $750-760$ & $\mathrm{p}$ & $-61 \pm 0(2)$ & $6.55 \pm 4(2)$ & $3.88 \pm .00(2)$ & $3.6 \pm 2(2)$ & $79 \pm 1(2)$ \\
\hline $760-770$ & $\mathrm{p}$ & $-62 \pm 4(4)$ & $8.90 \pm 7(4)$ & $2.67 \pm .76(4)$ & $9.2 \pm 10(4)$ & $96 \pm 20(4)$ \\
\hline $770-780$ & $\mathrm{p}$ & $-48 \pm 4(2)$ & $4.50 \pm 3(2)$ & $3.20 \pm .61(2)$ & $3.2 \pm 2(2)$ & $84 \pm 19(2)$ \\
\hline $780-790$ & $\mathrm{p}(2) / \mathrm{m}(1)$ & $-51 \pm 10(3)$ & $3.71 \pm 3(3)$ & $4.27 \pm .73(3)$ & $2.1 \pm 2(3)$ & $91 \pm 28(3)$ \\
\hline $790-800$ & $\mathrm{~m}$ & $-50 \pm 1(2)$ & $2.34 \pm 0(2)$ & $4.27 \pm .91(2)$ & $1.2 \pm .4(2)$ & $120 \pm 64(2)$ \\
\hline $800-810$ & $\mathrm{~m}$ & $-54 \pm 3(3)$ & $2.34 \pm 1(3)$ & $3.56 \pm .46(3)$ & $1.5 \pm .6(3)$ & $183 \pm 98(3)$ \\
\hline $810-820$ & $\mathrm{~m}$ & $\begin{array}{l}-60 \pm 3(3)^{*} \\
* 810-822 \mathrm{~m}\end{array}$ & $1.02 \pm .4(2)$ & $3.53 \pm .31(2)$ & $0.65 \pm .4(2)$ & $178 \pm 183(2)$ \\
\hline $820-830$ & $\mathrm{~m}(3) / \mathrm{d}(4)$ & $\begin{array}{c}50 \pm 4(2)^{*} \\
* 822-830 \mathrm{~m}\end{array}$ & $16.4 \pm 10(7)$ & $2.83 \pm .61(7)$ & $14.3 \pm 11(7)$ & $117 \pm 48(3)$ \\
\hline $830-840$ & $\mathrm{~m}$ & $-65 \pm 4(3)$ & $4.19 \pm 3(3)$ & $3.57 \pm .27(3)$ & $2.6 \pm 2(3)$ & $91 \pm 38(3)$ \\
\hline $840-850$ & $\mathrm{~m}$ & $-64 \pm 5(4)$ & $2.60 \pm 1(4)$ & $2.91 \pm .60(4)$ & $2.2 \pm 1(4)$ & $91 \pm 35(4)$ \\
\hline $850-860$ & $\mathrm{~m}$ & $-66 \pm 2(2)$ & $2.24 \pm 1(2)$ & $2.95 \pm .11(2)$ & $1.6 \pm 1(2)$ & $96 \pm 3(2)$ \\
\hline $860-870$ & $\mathrm{p}$ & $-34 \quad(1)$ & $15.6 \quad(1)$ & $3.07 \quad$ (1) & 11.0 & 87 (1) \\
\hline
\end{tabular}

Note: all uncertainties represent one standard deviation. Numbers in ( ) at right of each column signify the number of samples.

${ }^{a}$ Depth below water/sediment interface.

$\mathrm{b}=$ pillow basalt; $\mathrm{m}=$ massive flow; $\mathrm{d}=$ dike; $\mathrm{b}=$ breccia.

Stable inclination degrees.

$\mathrm{d}$ Intensity of natural remanent magnetization, NRM ( $\times 10^{-3}$ Gauss).

${ }_{\mathrm{f}}^{\mathrm{L}}$ Low-field susceptibility ( $\times 10^{-3}$ Gauss/Oe).

${ }_{\mathrm{g}}^{\mathrm{f}}$ Königsberger ratio, J $\mathrm{NRM} / 0.46 \chi$.

$\mathrm{g}_{\text {Median destructive alternating field of NRM. }}$ 

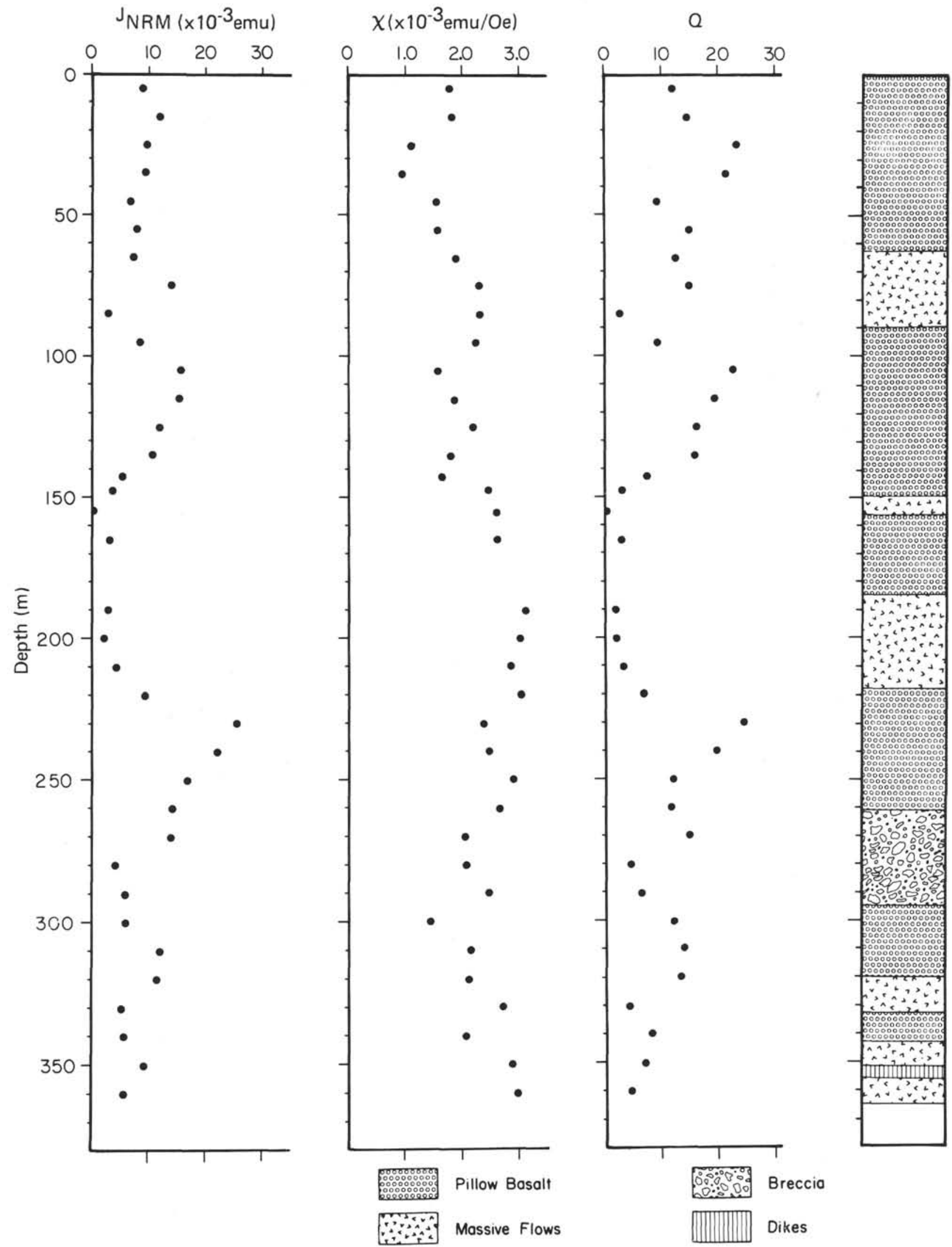

Figure 1. Downhole variation of $\mathrm{J}_{\mathrm{NRM}}, \chi$, and $\mathrm{Q}$ for Hole 417D. Data represent 10-meter averages; depth is measured from top of the igneous section. 


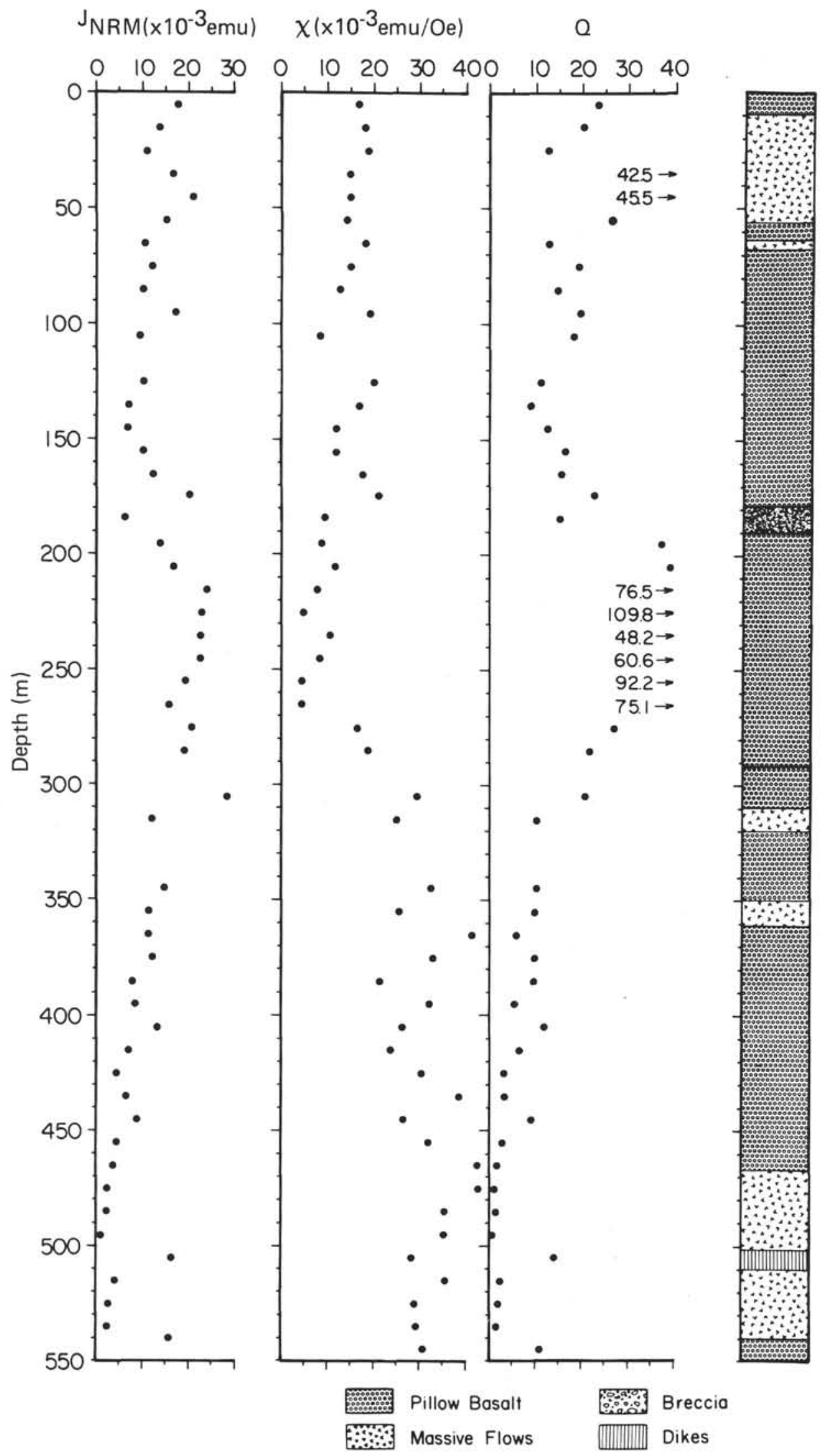

Figure 2. Downhole variation of $\mathrm{J}_{\mathrm{NRM}}, \chi, \mathrm{Q}$ for Hole $418 \mathrm{~A}$. All else is as in Figure 1. 


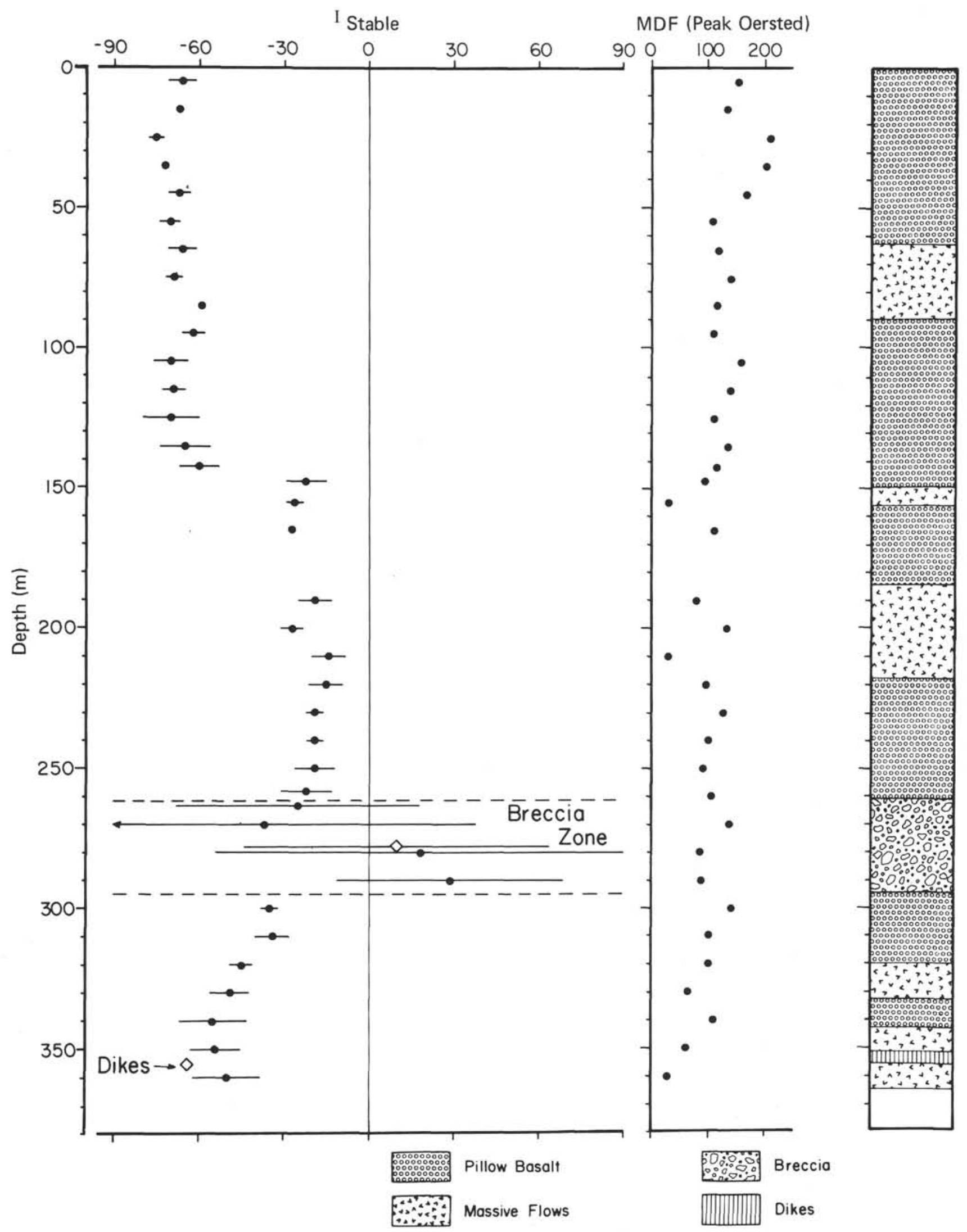

Figure 3. Downhole variations of ISTABLE and MDF for Hole 417D. Data represent 10-meter averages; depth is measured from the top of the igneous section; bars surrounding data represent one standard deviation. 


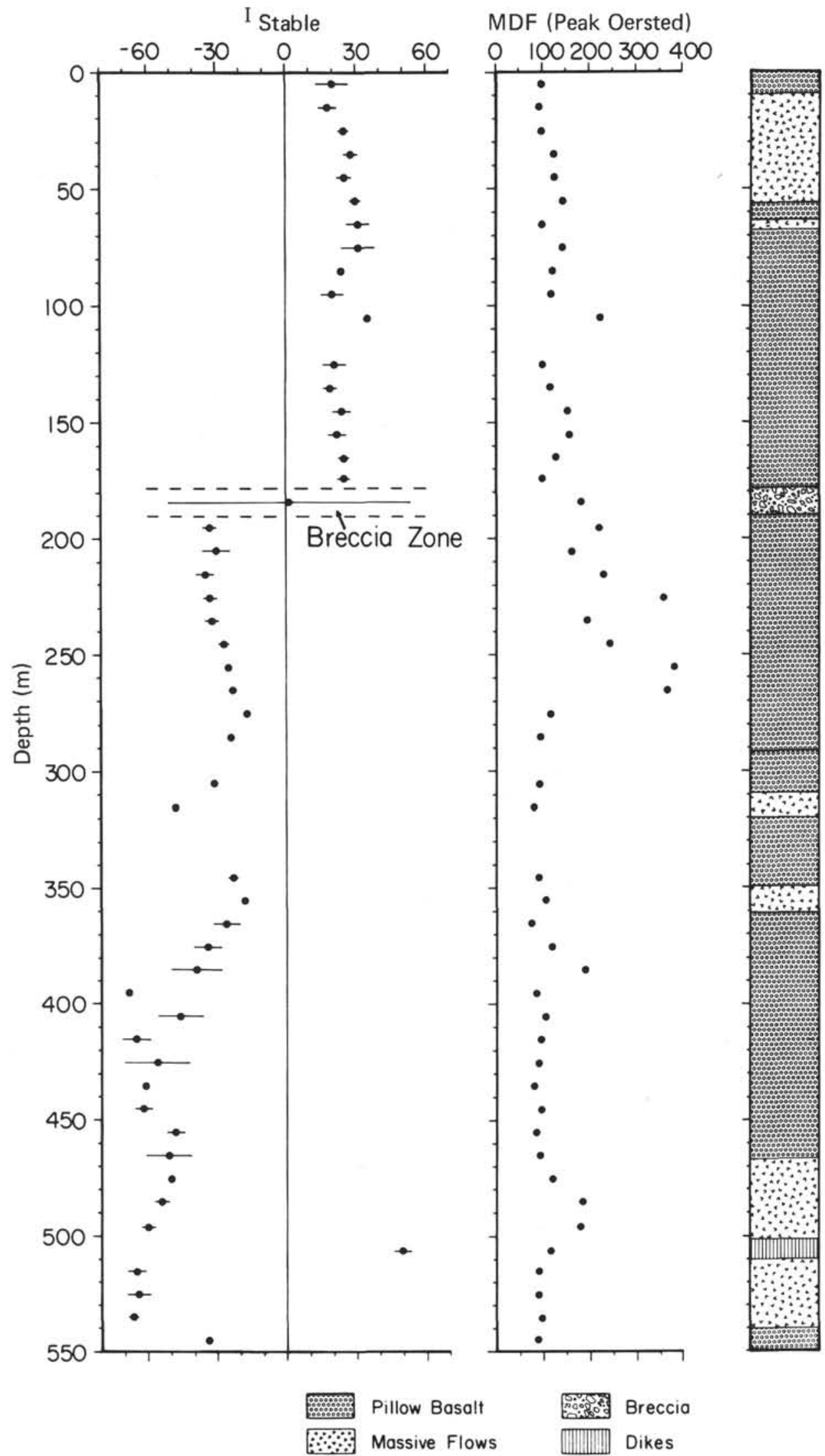

Figure 4. Downhole variation of ISTABLE and MDF for Hole 418A. All else is as in Figure 3. 
TABLE 2

Differences in Magnetic Properties of Various Lithologic Units, Hole 417D

\begin{tabular}{lcccrr}
\hline & $\begin{array}{c}\text { Thickness of } \\
\text { Section }(\mathrm{m})\end{array}$ & $\bar{J}_{N R M^{\mathrm{a}}}$ & $\overline{\mathrm{x}}^{\mathrm{b}}$ & $\bar{Q}^{\mathrm{c}}$ & $\overline{\mathrm{MDF}}^{\mathrm{d}}$ \\
\hline Pillows & 228.5 & $10.9 \pm 5.6$ & $1.94 \pm .51$ & $14.0 \pm 6.0$ & $130 \pm 32$ \\
Flows & 98 & $4.77 \pm 3.53$ & $2.78 \pm .28$ & $4.1 \pm 4.0$ & $71 \pm 45$ \\
Dikes & 4 & 17.0 & 2.29 & 16.1 & 172 \\
\hline
\end{tabular}

Note: Uncertainties represent one standard deviation.

${ }^{\mathrm{a}}$ Intensity of natural remanent magnetization, NRM ( $\times 10^{-3}$ Gauss).

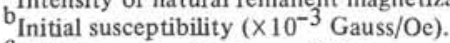

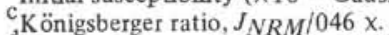

${ }^{\mathrm{d}}$ Median demagnetizing field of NRM (Oe).

for SD particles. Hence, particle size considerations alone suggest that $Q, J_{N R M}$, and MDF should generally show positively correlated profiles, and $\chi$ should exhibit a relative increase for MD over SD particles. Clearly, the above assumptions are not expected to be strictly valid; that is, fluctuations in the density, initial composition, and oxidation state of the magnetic minerals are known to occur and these would "contaminate" the simplified profiles expected from the above discussion. However, the data of Table 2, showing the differences in the average magnetic properties of the various lithologies (different particle sizes) of Hole 417D, and the general features of the downhole profiles of Holes 417D and 418A, are consistent with the preceding discussion, suggesting that particle size fluctuations of the magnetic minerals provide significant control on the magnetic properties of samples from these holes.

Histograms of $J_{N R M}, \chi$ and $Q$ for Holes 417D and 418A are shown in Figure 5; histograms of the MDF values are shown in Figure 6. The respective mean and median values of these parameters are listed in Table 3. It is interesting to note that the hole-average values for $Q$ are 11 and 22 for Holes 417D and 418A, respectively, implying that remanent magnetism is far more significant than induced moment in contributing to the magnetic anomaly. Even for the massive flows of Hole $417 \mathrm{D}, \bar{Q}=4$ (Table 2).

\section{Natural Remanent Magnetization (NRM): Implications for Magnetic Anomalies}

The NRM data are of primary importance for evaluating and understanding the source layer responsible for the marine magnetic anomalies. It is significant that the $\bar{J}_{\text {NRM }}$ value of each of the holes (Holes 417D and 418A) is more than twice that of previous Atlantic sites where significant penetration into the igneous basement had been achieved (e.g., Sites 332 through 335, Leg 37, Ryall et al., 1977; Site 395, Hole 395A and Site 396, Legs 45 and 46, Johnson, 1979; Peterson, 1979; Sites 407 through 413, Leg 49, Faller et al., 1979). This is particularly interesting, since the age of Holes 417D and 418A ( 108 m.y.) is more than twice that of any of the sites mentioned above. The arithmetic means of $J_{\text {NRM }}$ for Holes 417D and 418A are $9.2 \times 10^{-3}$ Gauss and $12.4 \times 10^{-3}$ Gauss, respectively (see Table 3 ).

To determine the coherent contribution of each hole to the observed magnetic anomaly, the net vertical component of remanence was calculated by obtaining the vertical NRM component for each 10-meter interval, and from these values the vertical contribution for each hole was determined.
For Hole 417D, the overall vertical component of magnetization is $-4.13 \times 10^{-3}$ Gauss, consistent with the reversed sense of anomaly $M 0$. This calculation assumes no contribution to the magnetization of the breccia zone from 606.5 to 640 meters sub-bottom, for which $I_{\text {NRM }}=17^{\circ} \pm 49^{\circ}$ and $I_{\text {STABLE }}=10^{\circ} \pm 54^{\circ}$. Table 4 details the contributions of the various lithologies - pillow basalts, massive flows, brecciated zone, and dikes - to the vertical remanence component. For Hole 417D, the pillows are the chief contributors to the anomaly; the contribution of the massive flows is almost zero and opposite to the sense of the anomaly.

All other conditions being equal, more viscous remanent magnetization (VRM) will be produced in a specimen when the external field is applied antiparallel than when applied parallel to the direction of the primary remanence. Therefore, more positive VRM is produced in negatively magnetized than in positively magnetized oceanic blocks. This difference in the VRM contribution would be greatest for young crust for which sea-floor spreading and plate rotations can be more readily neglected and where this difference in VRM has not been masked by many previous reversals. Thus, the presence of magnetically "soft" massive flow units within the extrusive oceanic Layer 2 provides an additional mechanism for reducing the magnetization contrast of oppositely magnetized blocks; this also would contribute to the rapid reduction in the amplitude of the marine magnetic anomalies away from spreading centers.

The value of $\bar{Q}$ for the massive flow specimens of Hole 417D is 4.1 (Table 2), suggesting that even for these relatively unstable specimens remanence is dominant over induced magnetization. Although the dispersion is great, INRM for the massive flows of Hole 417D is not significantly different from the inclination at the sampling site expected from normally polarized geocentric axial dipole. (It will be seen later that the stable inclinations of the massive flows of Hole 417D are of reversed polarity, consistent with the sense of anomaly $M 0$.) These results imply that, although the contribution of induced magnetization (of time constants on the order of laboratory time scale) is relatively minor, the coherent magnetization of Hole 417D is significantly reduced by VRM parallel to the present field. Lowrie (1973) obtained similar data and reached similar conclusions.

Because Hole 418A is composed mainly of two oppositely magnetized sections, the hole-average, vertical component of $J_{N R M}$ is only $-2.19 \times 10^{-3}$ Gauss; this reduced component is consistent with mixed polarities expected in sections near anomaly boundaries. If the hole-average vertical component of remanence is calculated for Hole 418A, assuming that all the inclinations are negative, one obtains $-5.99 \times 10^{-3}$ Gauss. The large difference in the vertical component of remanence between Holes 417D and 418A is caused by fluctuations in the intensity and direction of the geomagnetic field and by differences in the magnetic properties of the rocks composing each section. If such differences are coherent over several kilometers (comparable to the distance between the source and the observer), they would influence the shapes and amplitudes of the sea surface magnetic anomalies. However, if these differences are averaged out over distances of several kilometers, they would not be seen at the sea surface. The results from Holes 417D and 418A suggest that certain smaller scale features of 

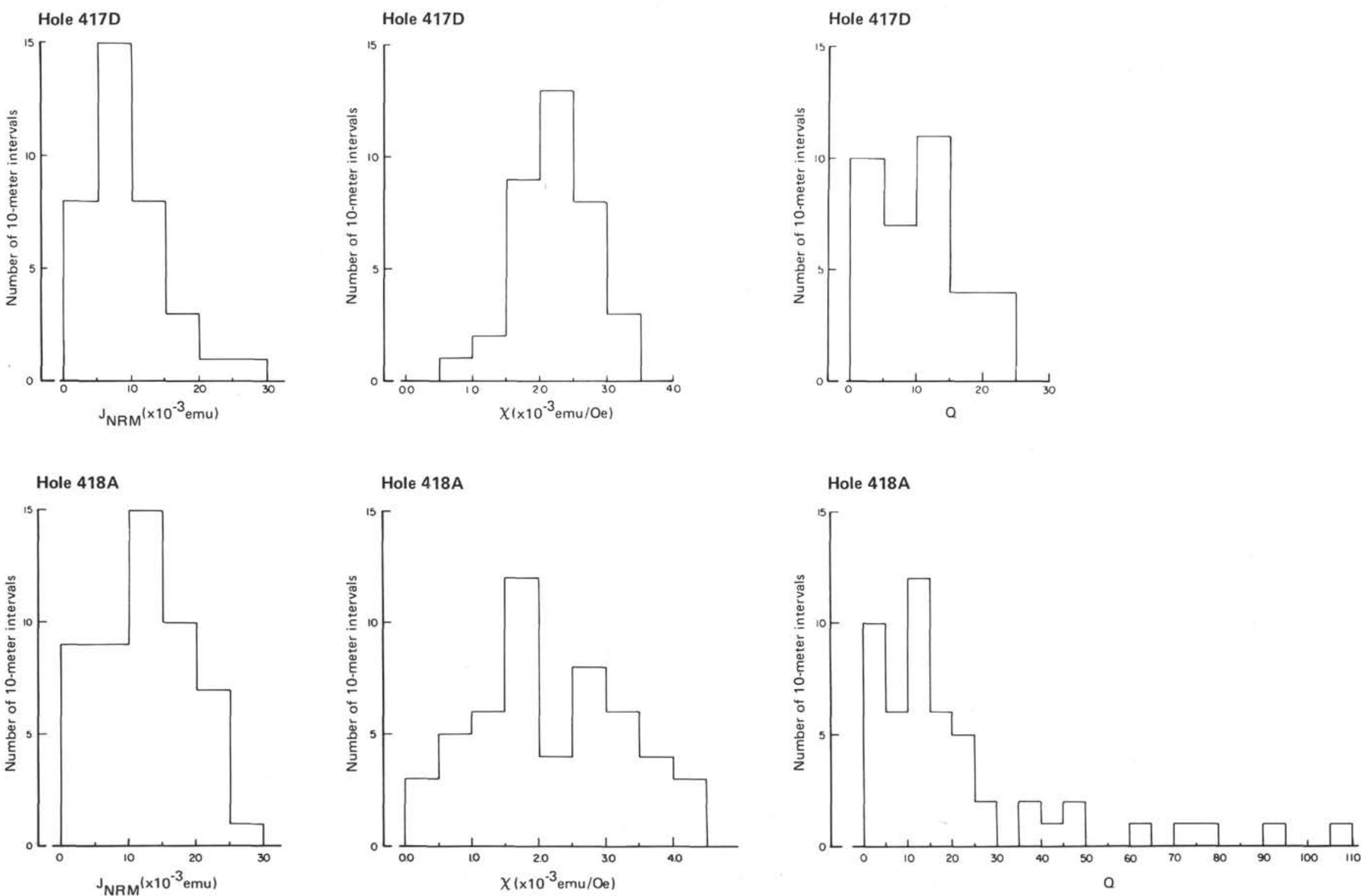

Figure 5. Histograms of $\mathrm{J}_{\mathrm{NRM}}, \chi, \mathrm{Q}$ for Holes $417 \mathrm{D}$ and 418 A. (Note that the abscissas are linear.) 

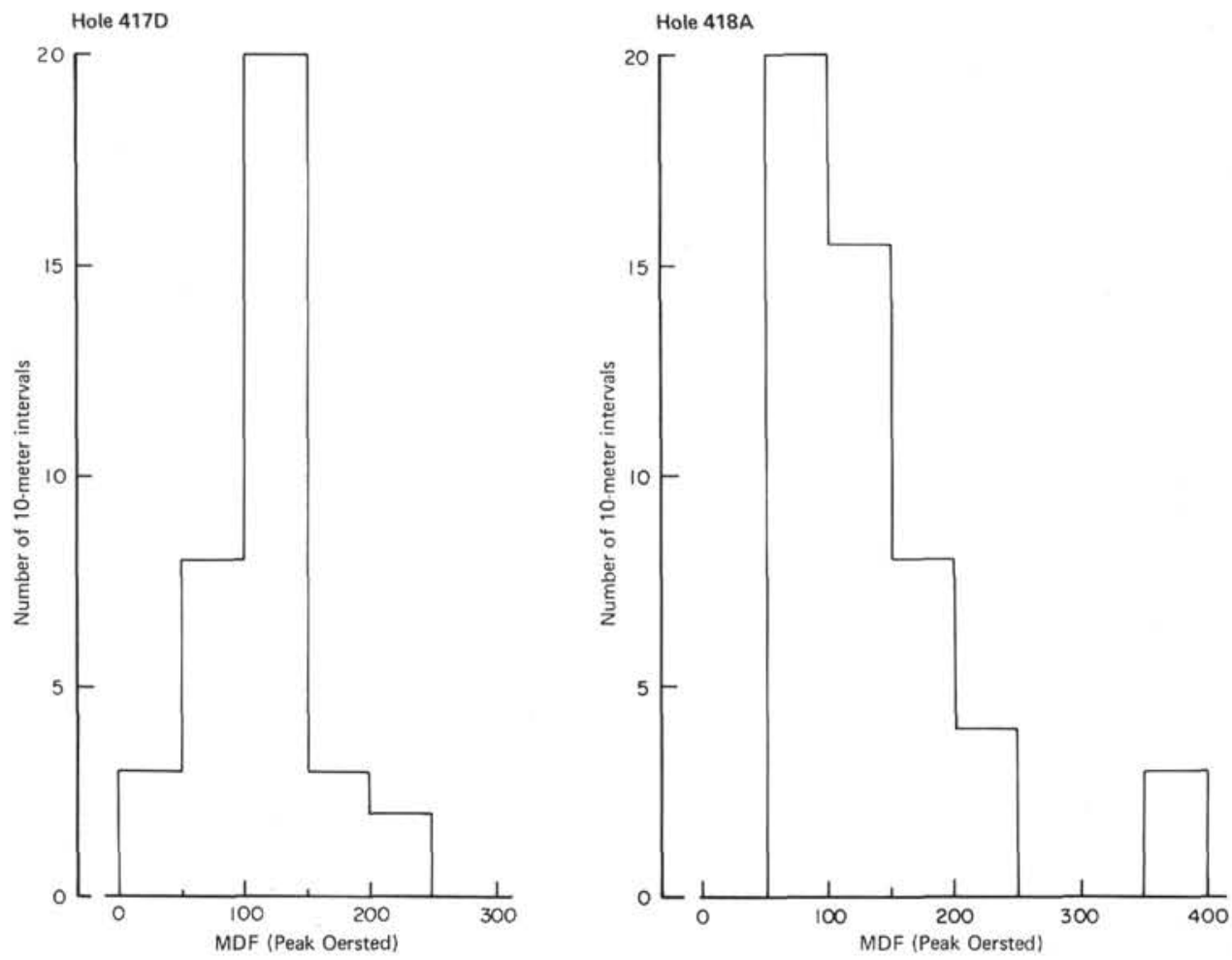

Figure 6. Histograms of MDF's for Holes $417 \mathrm{D}$ and $418 \mathrm{~A}$.

TABLE 3

Magnetic Properties, Hole Averages

\begin{tabular}{|c|c|c|c|c|c|c|c|c|c|}
\hline \multirow[b]{2}{*}{ Hole } & \multirow[b]{2}{*}{$\mathrm{N}^{\mathrm{a}}$} & \multicolumn{2}{|c|}{$\bar{J}_{N R M}^{\mathrm{b}}$} & \multicolumn{2}{|c|}{$\bar{x}^{c}$} & \multicolumn{2}{|c|}{$\bar{Q}^{\mathrm{d}}$} & \multicolumn{2}{|c|}{$\overline{\mathrm{MDF}}^{\mathrm{e}}$} \\
\hline & & Mean $\pm s$ & Median & Mean $\pm s$ & Median & Mean $\pm s$ & Median & Mean $\pm s$ & Median \\
\hline 417D & 36 & $9.2 \pm 5.6$ & 8.7 & $2.20 \pm 0.55$ & 2.20 & $11 \pm 7$ & 12 & $112 \pm 41$ & 110 \\
\hline $418 \mathrm{~A}$ & 51 & $12.4 \pm 6.6$ & 12.1 & $2.17 \pm 1.06$ & 1.93 & $22 \pm 24$ & 13 & $140 \pm 72$ & 117 \\
\hline
\end{tabular}

${ }^{\mathrm{a}}$ Number of 10 -meter intervals.

$\mathrm{b}_{\text {Intensity of natural remanent magnetization, NRM ( }}{ }^{-3}$ Gauss).

Initial susceptibility ( $\times 10^{-3}$ Gauss/Oe).

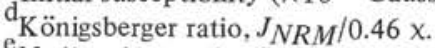

Median destructive field of NRM (Oe).

TABLE 4

Vertical Component of NRM, Hole 417D

\begin{tabular}{lccc}
\hline Lithology & $\begin{array}{c}\text { Unit } \\
\text { Thickness } \\
(\mathrm{m})\end{array}$ & $\begin{array}{c}\text { Vertical NRM } \\
\text { Component-Average } \\
\text { per Lithology } \\
\left(\times 10^{-3} \text { Gauss }\right)\end{array}$ & $\begin{array}{c}\text { Vertical NRM } \\
\text { Component-Normalized } \\
\text { to Entire Hole } \\
\left(\times 10^{-3} \text { Gauss }\right)\end{array}$ \\
\hline Pillow basalts & 228.5 & -6.62 & -4.06 \\
Massive flows & 98 & +0.36 & +0.10 \\
Breccia & 33.5 & - & -0.17 \\
Dikes & 4 & -15.3 & -4.13 \\
Overall & 364.0 & - & \\
\hline
\end{tabular}

magnetic profiles are caused by heterogeneities in the magnetic properties of the rocks forming oceanic Layer 2 and are not related to geomagnetic or topographical features.

The high values of $J_{N R M}$ (Table 3 ) and the coherence of its vertical component suggest that the magnetic profiles in the vicinity of Sites 417 and 418 can be completely accounted for by sources in the upper 1 kilometer of Layer 2. (Detailed computations are in progress.)

\section{Stable Directions of Remanent Magnetism: Implications for Oceanic Crust Formation}

Directions of stable remanence are among the more interesting Leg 52 paleomagnetic results. These were obtained from alternating field (AF) demagnetization curves. Often, the stable end point is fairly easy to select as the stable direction; however, in some Leg 52 samples the primary remanence (negative inclinations) was superimposed by secondary, positive inclination remanence, of, presumably, viscous or chemical origin. Because the secondary magnetization was typically "softer" than the primary, it could often be removed by AF demagnetization. However, sometimes the primary remanence was not uncovered until less than 10 per cent of natural remanence remained, and one cannot then be certain that all the secondary remanence has been removed. Thus, it is possible that 
the final direction, which is designated as "stable," still includes an unknown but significant component of stable secondary remanence. Hence, in these samples, the "stable" negative inclinations might be biased toward negative inclination values that are too shallow, because of possible overprinting by a stable secondary component of positive inclination. This effect would be more pronounced in the magnetically "softer"' samples - for example, some of the massive flows of Hole 417D.

Assuming that the Bermuda Triangle has formed a rigid part of the North American plate since Cretaceous time, then, using Mankinen's (1978) average North American Cretaceous paleomagnteic pole position $\left(68^{\circ} \mathrm{N}, 186^{\circ} \mathrm{E}\right)$, one obtains a paleoinclination of $\pm 32^{\circ} \mathrm{N} \pm 4^{\circ}$ with a corresponding paleolatitude of $17^{\circ} \mathrm{N}$ for Sites 417 and 418 .

Figure 5 shows the downhole variation of the stable inclinations in Hole 417D. The upper 145 meters is a tightly clustered distribution whose mean inclination is $-67^{\circ}$ with a standard deviation of $\pm 4^{\circ}$, and the underlying 116.5-meter section has a value of ISTABLE $=-21^{\circ} \pm 4^{\circ}$. The boundary between these inclination-defined sections is very sharp and occurs within lithologic Unit 5, which is a 6-meter-thick sequence of pillow basalts. Composed of rubble and broken rock, this boundary occurs in Core 42 between the bottom of Section 4 and the top of Section 5 (for Sample 417D-42$4,108-110 \mathrm{~cm}$, ISTABLE $=-60^{\circ}$ and for Sample 417D-42-5, $45-47 \mathrm{~cm}$, ISTABLE $=-22^{\circ}$ ). These two sections are underlain by a 33.5-m-thick zone of brecciated pillowed flows for which ISTABLE $=10^{\circ} \pm 54^{\circ}$ and which overlies a 70 -meter section down to the bottom of Hole 417D having a value of IsTABLE $=-46^{\circ} \pm 9^{\circ}$. Two high-angle dikes intrude into Core 68 and yield IsTABLE $=-64^{\circ} \pm 2^{\circ}$ in four samples. The above stable inclination data are summarized in Table 5. Application of the t-test to the mean stable inclinations of the dikes and the section which they intrude shows that they are distinct at the 99 per cent confidence level.

The average stable inclination of the upper 145 meters of Hole 417D deviates about $35^{\circ}$ from the inferred Cretaceous paleoinclination. It is not possible to use the inclination data to determine whether the cause of this deviation is a geomagnetic fluctuation or a tectonic rotation of this section, or both. However, the dikes occurring at the bottom of Hole 417D are clearly younger than the material they intrude, and their average stable inclination is very similar to that of the uppermost 145-meter section. This suggests that the steep inclinations represent a geomagnetic fluctuation, since it is difficult to imagine the upper 145-meter and the lower 70-meter sections undergoing substantial rotation with the intervening 116.5-meter section remaining unmoved. It is possible that the dikes are part of the feeder system associated with the upper 145-meter section. Unfortunately, there are at the present no geochemical or petrological data available either contradicting or supporting this possibility (W. Bryan, private communications, 1979).

Analysis of the shipboard magnetic anomaly profiles (Schouten, 1976) showed that Hole 418A was drilled very close to the eastern (younger) boundary of anomaly $M 0$. Figure 6 shows the inclination stratigraphy of Hole 418A. The upper 178-meter section has a positive stable inclination, IsTABLE $=+25^{\circ} \pm 5^{\circ}$. The lower boundary of this section coincides with the boundary between Units 5 and $6 \mathrm{~A}$. Unit $6 \mathrm{~A}$ consists of pillow breccia whose ISTABLE $=1^{\circ} \pm 52^{\circ}$.
Below the breccia zone is a 200 -meter-thick section having ISTABLE $=-29^{\circ} \pm 8^{\circ}$. The lower boundary of this inclination section occurs within Unit 11, between Samples 65-3, 17 $\mathrm{cm}$ and $65-6,13 \mathrm{~cm}$. (The data for the later specimen were obtained by Dr. Rigotti as part of the Leg 53 shipboard results: Initial Core Descriptions, Deep Sea Drilling Project, Legs 51-53, 1977, p. 360). Considerable brecciation, broken rocks, and rubble occur in the three sections of Core 65 between these two samples; more work is required to better define this boundary. The next lower section extends from 390 to 540 meters below the sediment/basalt interface, and its ISTABLE $=-58^{\circ} \pm 7^{\circ}$. Within this section is an 8 -meter-thick unit, from 502 to 510 meters below the sediment/basalt interface, consisting primarily of dikes whose stable inclination is $+50^{\circ} \pm 4^{\circ}$. The lowest 8 meters cored in Hole 418A, equivalent with Unit 14, has IsTABLE $=$ $-34^{\circ}$.

Site 417 was located near the center of negative anomaly $M 0$ and its stable inclinations are, without exception, consistent with the sense of the anomaly. (See Appendix regarding the omission of two samples from each hole.) The positive stable inclinations capping the basalts of Hole $418 \mathrm{~A}$ are consistent with the hole's proximity to the anomaly boundary. This shows that the magnetized blocks producing the anomalies do not have vertical boundaries, but are more likely to be wedge-shaped with younger material overlying older basalts. The positive inclinations found lower in the core are evidence for the irregular nature of the boundary between oppositely magnetized blocks. None of these observations is surprising in view of the proximity of Hole $418 \mathrm{~A}$ to the anomaly boundary and the fact that the build-up of the extrusive layer of the oceanic crust has taken finite time.

Figures 5 and 6 show that Holes 417D and 418A are built up of several sections in which the stable inclinations are relatively uniform but whose mean values are distinct. This is illustrated in Figures 7 and 8 by histograms of the stable inclinations for Holes 417D and 418A, where different stip-

TABLE 5

Stable Inclinations

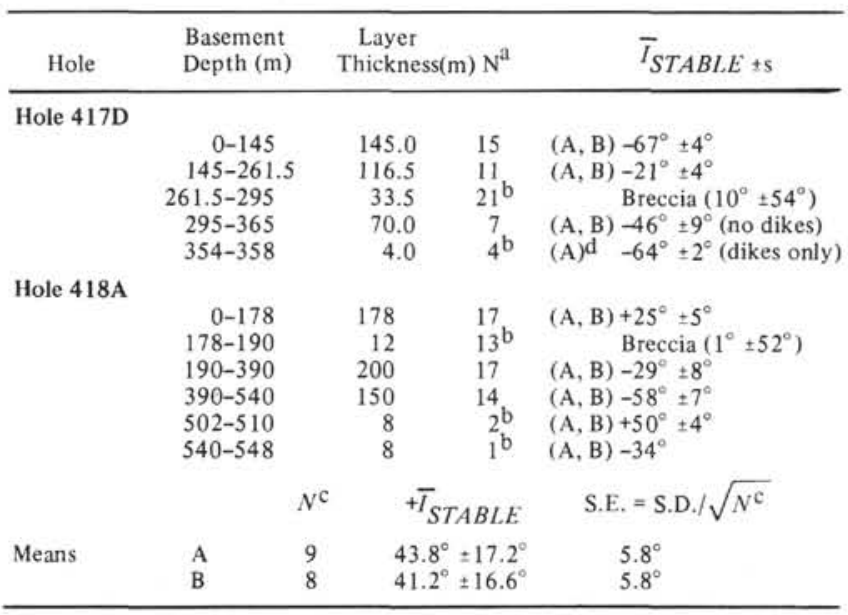

Number of 10 -meter intervals.

Number of individual samples.

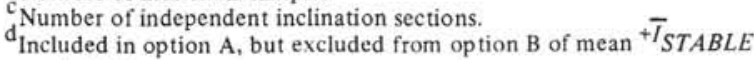
calculation. 


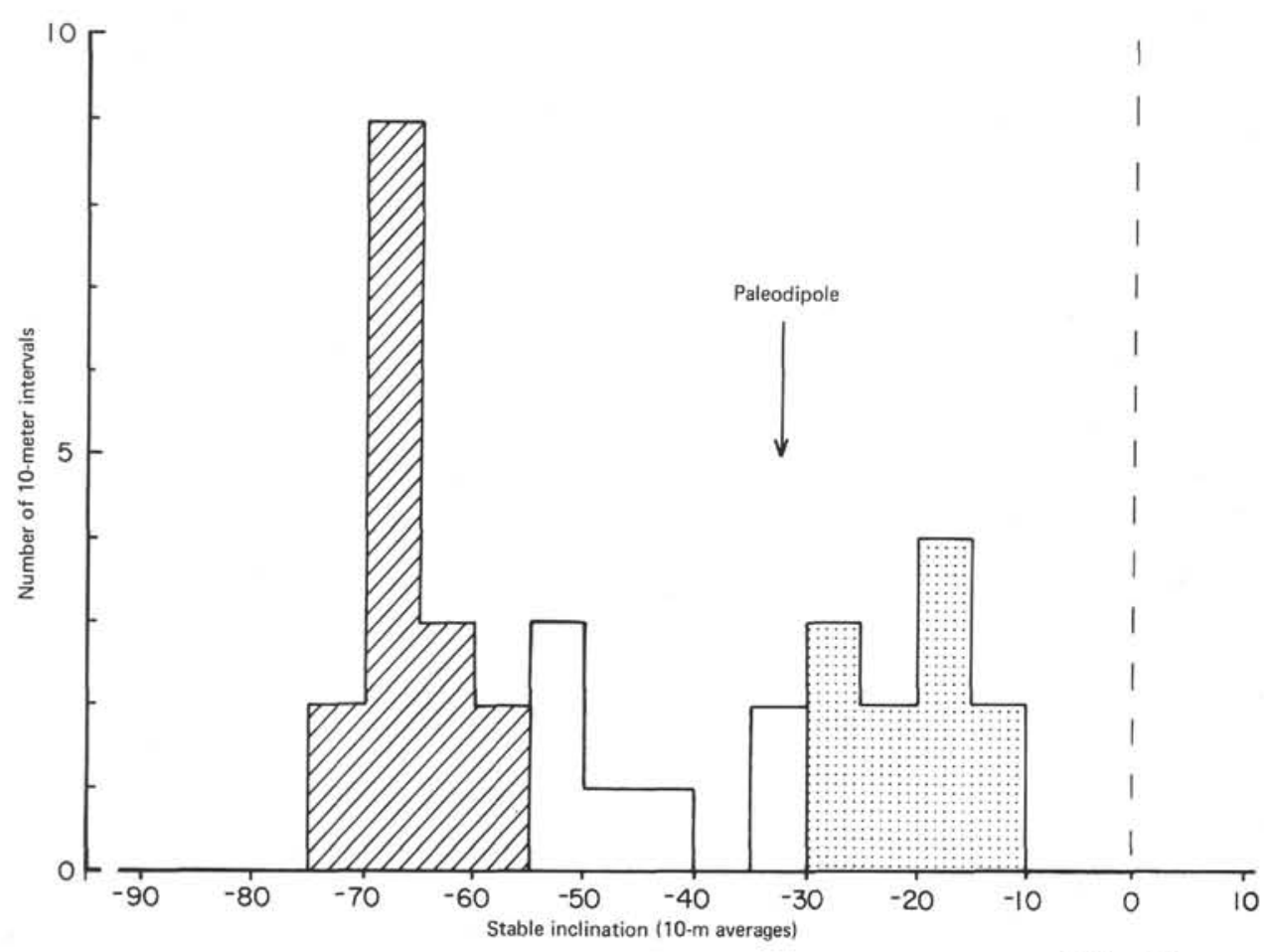

Figure 7. Histogram of ISTABLE for Hole $417 \mathrm{D}$. Paleoinclination is $\pm 32^{\circ}$. 10-meter intervals which belong to a single, contiguous section of the hole are designated by the same stipple pattern.

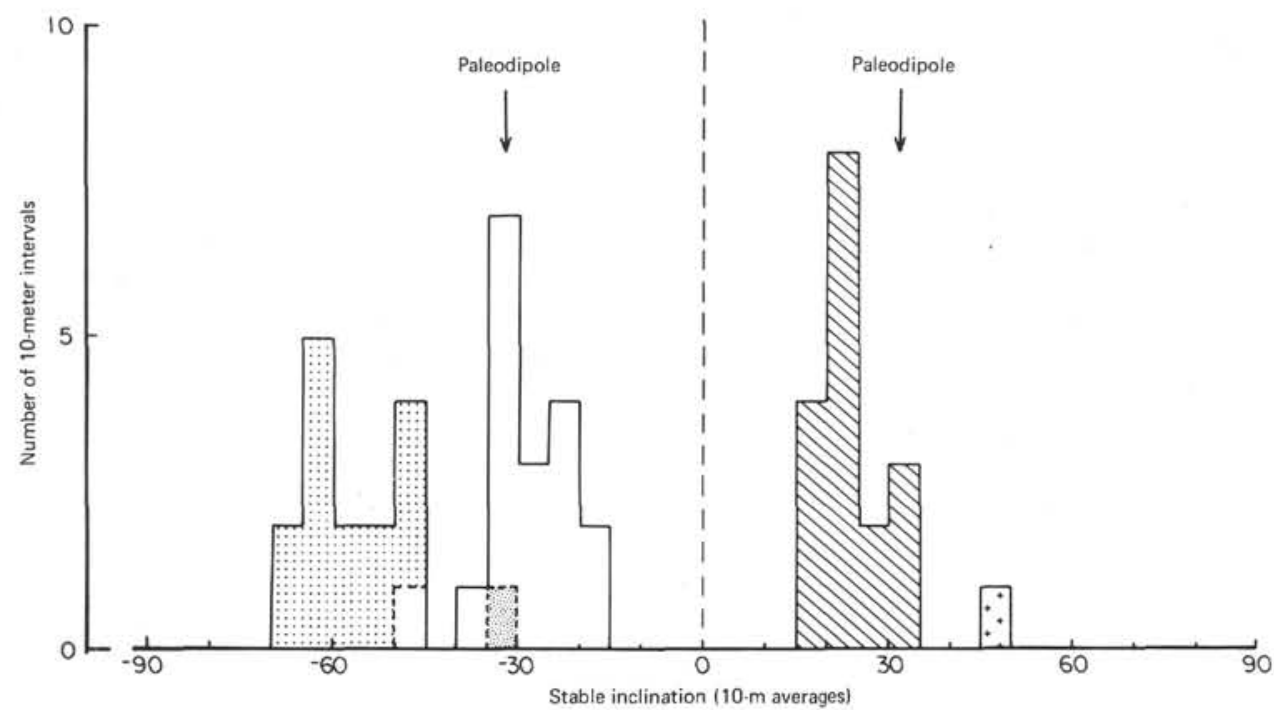

Figure 8. Histogram of $\mathrm{I}_{\mathrm{STABLE}}$ for Hole 418A. All else is as in Figure 7.

ple patterns indicate different inclination sections. For Hole 417D, there are three sections of relatively uniform stable inclination, which do not overlap on the histogram. (Because the dikes' ISTABLE is similar to that of the uppermost 145 -section, they are not considered as an independent inclination unit.) For Hole $418 \mathrm{~A}$, with the exception of one point spilling over, adjacent inclination sections also plot in distinct fields on the histogram. Because of the relatively large difference in their mean stable inclinations and their separation in the vertical column, the two regions of posi- tive inclination in Hole 418A are considered as distinct recordings of the geomagnetic field. Application of the t-test to pairs of ISTABLE sections of Holes 417D and 418A shows that the hypothesis that any two IsTABLE values are equal must be rejected at the 99 per cent confidence level.

Because the adjacent sections of core which have relatively uniform ISTABLE are always separated by zones of brecciation, rubble, and broken rock, and since the average ISTABLE values of adjacent sections are statistically distinct and have relatively small dispersions (see Table 5), each 
inclination section is considered to represent a single pulse of volcanism, providing an instantaneous reading of the paleomagnetic field. In Holes 417D and 418A such volcanic episodes produce sections that are often from 150 to 200 meters thick. The period needed to form an approximately 200 -meter section of uniform inclination is indeterminate but probably is anywhere from less than one year to several hundred years. However, the total time represented by the entire igneous column cored in each of Holes 417D and $418 \mathrm{~A}$ is probably at least several thousand years. The best evidence for this is the presence in Hole 418A of stableinclination sections representing both polarities of the geomagnetic field, it being thought that several thousand years ( 2000 to 5000 years) are required to produce a complete field reversal (Harrison and Somayajulu, 1966; Opdyke et al., 1973).

Although Holes 417A and 417D and Holes 418A and $418 \mathrm{~B}$ are in close proximity, it is unlikely that they yielded samples of contemporaneous volcanic eruptions. This is supported by recent observations at the FAMOUS area on the Mid-Atlantic Ridge near $37^{\circ} \mathrm{N}$, where flow regions have an average width of between 500 and 800 meters (Ballard and Van Andel, 1977). Furthermore, the half spreading rate near Sites 417 and 418 is about $1.8 \mathrm{~cm} / \mathrm{y}$ (Carle, 1976), which implies that holes whose component of separation along the direction of spreading is 180 meters have an average age difference of about 10,000 years.

Considering each inclination section of Hole 417D and $418 \mathrm{~A}$ as an independent recording of geomagnetic inclination, we calculated ISTABLE for two groupings of the paleoinclinations (see Table 5). Option A considers the dikes of Hole 417D as an independent paleoinclination, whereas option B, which is preferred, considers these dikes as feeding the upper 145-meter section of Hole 417D and hence recording the same paleoinclination. Although the bottom inclination section of Hole 418A is represented by only one sample, it is used in the above analysis since measurements of this sample are in excellent agreement with several samples from this depth interval measured on Leg 53 (Initial Core Descriptions, Deep Sea Drilling Project, Legs 51-53, 1977, pages 417 and 418). The mean inclination values have not been corrected for apparent shallowing resulting from lack of azimuthal orientation, because the effect is small $\left(<1^{\circ}\right)$ for latitudes less than $25^{\circ}$ (Cox, as referenced in Peirce, 1976). +ISTABLE for the two options are $43.8^{\circ} \pm 17.2^{\circ}$ and $41.2 \pm 16.6^{\circ}$, respectively, both of which are steeper than the paleoinclination. However, the Cretaceous paleoinclination is included in twice the standard error of +ISTABLE of both options; therefore, I conclude that there is no significant difference between them and the Cretaceous paleoinclination.

I shall now examine whether the observed stable inclinations of Holes 417D and 418A are explainable by normal geomagnetic secular variation (SV). McElhinny and Merrill (1975) analyzed the available paleomagnetic data for the past $5 \mathrm{~m} . \mathrm{y}$., and for a latitude of $17^{\circ}$ they obtained an angular dispersion of about $13.6^{\circ}$ for virtual geomagnetic poles (VGPs). Assuming the latter follow Fisher's distribution (Fisher, 1953), their angular dispersion can be converted to angular dispersion of field directions according to Cox (1970). Thus, one obtains an angular dispersion of field directions of $17.5^{\circ}$ for a latitude of $17^{\circ}$. Alternatively, using Creer's (1962) transformation equation, an angular dispersion of field directions of $18.6^{\circ}$ results. Irving and Pullaiah (1976) showed that during Cretaceous time the geomagnetic SV was less than during the past $65 \mathrm{~m} . \mathrm{y}$. However, this conclusion is significantly influenced by the much diminished SV during the Cretaceous "quiet zone" from about 108 to $80 \mathrm{~m}$.y. ago, for which the equatorial angular dispersion of field directions is $14.7^{\circ}$. But for the past 65 m.y. this value is about $19^{\circ}$; therefore, Irving and Pullaiah's equatorial angular dispersion for the Cretaceous $\left(\sim 16^{\circ}\right)$ is probably too low and not representative of the SV at Sites 417 and 418 , which are in anomaly $M 0$, just prior to the Cretaceous "quiet zone." Hence, assuming that the geomagnetic SV during the time of igneous activity at Sites 417 and 418 was similar to the SV of the past 65 m.y., and because they all are within $35^{\circ}$ of the inferred paleoinclinations, the stable inclinations of Hole 417D and 418A likely result from normal geomagnetic SV, since all are within $35^{\circ}$ of the inferred paleoinclination.

\section{Paleoinclinations and Tectonic Rotations of the Volcanic Sections}

I have included this section because some investigators have used the stable inclinations of Holes 417D and 418A as evidence for tectonic rotations in the oceanic crust. Although it is well known that such rotations are ubiquitous manifestations of geological processes - both continental and submarine - they cannot normally be ascertained solely from paleomagnetic directions of volcanic sections, and much less so if the data are restricted to paleoinclinations. The question remains whether the dispersion of the stable inclinations in Holes 417D and 418A is consistent with the ever-present geomagnetic SV or whether it requires the introduction of the additional parameter of tectonic rotation. Although insufficient for a choice between these alternatives, the data available suggest that, strictly from a paleomagnetic point of view, it is unnecessary to introduce a tectonic component of dispersion of the stable inclinations of Holes 417D and 418A. The more pertinent pieces of evidence are:

1) The mean stable inclination of Holes 417D and 418A is $41.2^{\circ}$ (S.D. $=16.6^{\circ}$ and S.E. $\left.=5.8^{\circ}\right)$, which is not significantly different at the 95 per cent confidence level from their inferred Cretaceous paleoinclination.

2) The stable inclination of the dikes at the bottom of Hole $417 \mathrm{D}$ is $-64^{\circ}$ (S.D. $=2^{\circ}$ ). This is essentially identical to the stable inclination of the uppermost 145-meter section for which ISTABLE $=-67^{\circ}\left(\mathrm{S} . \mathrm{D} .=4^{\circ}\right)$, which is the stable inclination furthest removed from both the mean stable inclination and the inferred paleoinclination. Furthermore, the vertical separation of the dikes from the bottom of their inclination-equivalent section is more than 200 meters, and one of the intervening stable inclination sections has ISTABLE $=-21^{\circ}$ (S.D. $=4^{\circ}$ ).

3) All the stable inclinations of Holes 417D and 418A are within $35^{\circ}$ of the inferred Cretaceous paleoinclination (the paleolatitude is about $17^{\circ}$ ). Although most of the presently accepted models of geomagnetic secular variation dict that the angular dispersion of paleomagnetic directions will decrease with increasing paleolatitude, deviations 
greater than $35^{\circ}$ from the paleoinclination occur in about 10 per cent of untilted (or tilt-corrected) lavas on Iceland, whose paleolatitude is about $65^{\circ}$ (Wilson et al., 1972; Harrison and Watkins, 1977); and such deviations are observed also in the Columbia River basalts (Rietman, 1966; Watkins and Baksi, 1974) whose paleolatitude is about $45^{\circ}$.

Although tectonic rotations may indeed contribute to the observed scatter of stable inclinations, the presence of such rotations must be proven by other than paleomagnetic evidence, because the diversity of geomagnetic behavior is ample to completely account for the stable inclinations of Holes 417D and 418A.

\section{Breccia Zones}

Several breccia zones occur in Holes 417D and 418A. In Hole 417D, samples from Section 57-2 through Core 61 (a 33.5-section of broken pillows and pillow breccia) exhibit highly scattered $I_{N R M}$. Significantly, the dispersion does not diminish upon AF cleaning: $I_{N R M}=17^{\circ} \pm 49^{\circ}$ and $I_{\text {TABLE }}=$ $10^{\circ} \pm 54^{\circ}$. The pillow breccia recovered in Hole $418 \mathrm{~A}$, Section 40-2 through Section 42-1 from approximately 498 to 510 meters sub-bottom, also has highly scattered inclinations: both $I_{N R M}$ and ISTABLE are $\sim 1^{\circ} \pm 52^{\circ}$. The large dispersion of the inclinations of these two breccia zones suggests that neither possesses a coherent remanence direction and, except for induced magnetization, they will not contribute a net magnetic signal to the oceanic layer containing them. Two additional "minor'" intervals of brecciation $(<5 \mathrm{~m}$ thick) in Hole 418A were sampled for paleomagnetism.

The considerable scatter of the inclinations of the zones of brecciation and broken rock suggests that brecciation occurred at temperatures below the blocking temperatures of the pillow basalts. Further evidence for this was sought by obtaining several pairs of specimens, each pair from a single contiguous rock piece, to allow for direct comparisons of both the inclination (I) and declination (D) of the two specimens. One member of each pair consists of a single basalt clast and the other contains many small fragments in a clay matrix. Table 6 shows that for the four sample pairs from the two "major"' breccia zones of Holes 417D and 418A, the magnetic directions are discordant also on a small scale, supporting the above conclusion that brecciation occurred at temperatures below the blocking temperatures of the pillow fragments. A reasonable estimate for the upper limit of the brecciation temperature is $200^{\circ} \mathrm{C}$, which is suggested by the restricted compositional range of titanomagnetites in oceanic basalts, whose initial Curie points are near $150^{\circ} \mathrm{C}$ (Johnson and Hall, 1978). (Since all samples from Holes 417D and 418A had been oxidized at low temperature, they could not be used for determining the initial composition of the unoxidized titanomagnetite phase). Furthermore, had brecciation occurred after low-temperature oxidation, temperatures higher than $200^{\circ} \mathrm{C}$ would have caused breakdown and disproportionation of the titanomaghemite phase, whereas the observed thermomagnetic curves are characteristic of low-temperature-oxided titanomagnetites. In contrast, the specimen pair from the "minor" breccia zone in Core 28 of Hole 418A shows a coherent remanence direction with an inclination similar to that of the adjacent unbrecciated extrusives. This suggests that the brecciation in the vicinity of this specimen pair occurred at a temperature above the blocking temperatures of the basalt. This picture is complicated by the completely discordant inclination of a sample from the same brecciated zone only $30 \mathrm{~cm}$ above this specimen pair (see Levi et al., this volume). Possibly, this apparent temperature heterogeneity is due to localized flow of hot fluids. (Zones of brecciation at Sites 395 and 410 also appear to have been formed above the blocking temperatures of the basalts [Johnson, 1979; Steiner et al., 1979].)

\section{CONCLUSIONS}

The most important paleomagnetic results of Leg 52 are summarized below.

1) The stable inclinations of Hole $417 \mathrm{D}$ are negative throughout, consistent with the reversed sense of anomaly MO.

2) In Hole 418A, the positive inclination section capping the hole is consistent with its proximity to the anomaly boundary and suggests an inclined boundary between oppositely magnetized oceanic blocks where younger extrusives overlie older crust.

3) $J_{N R M}$ for Holes 417D and 418A is on the order of $10 \times$ $10^{-3}$ Gauss - about twice that of previous Atlantic DSDP sites. This is particularly noteworthy because the age of anomaly $M 0$ is about $108 \mathrm{~m} . \mathrm{y}$., which is more than twice that of any Atlantic DSDP site for which significant penetra-

TABLE 6

Remanence Properties of Breccia Zones

\begin{tabular}{lcrrrrl}
\hline $\begin{array}{c}\text { Sample } \\
\text { (Interval in cm })\end{array}$ & $\begin{array}{c}J_{N R M} \\
\left(\times 10^{-3} \text { Gauss }\right)\end{array}$ & $I_{N R M}$ & $D_{N R M}$ & $I_{S T A B L E}$ & $D_{S T A B L E}$ & \multicolumn{1}{c}{ Comments } \\
\hline Hole 417D & & & & & & \\
59-6, 62-64, 3A & 9.90 & 46 & 24 & 44 & 25 & Single clast \\
59-6, 70-73, 3A & 0.65 & -14 & 234 & -14 to +21 & 234 & Fragments in clay matrix \\
60-4, 46-49, 3A & 1.15 & 53 & 247 & 54 & 233 & Fragments in clay matrix \\
60-4, 59-62, 3A & 7.04 & -11 & 88 & 8 & 268 & Single clast \\
& & & & & & \\
Hole 418A & & & & & & \\
28-1, 42-45 & 0.87 & 23 & 163 & 23 & 162 & Fragments in clay matrix \\
28-1, 48-51 & 16.7 & 21 & 160 & 21 & 159 & Single clast \\
40-2, 4-7, 1A & 4.18 & 9 & -47 & 10 & -49 & Several clasts in clay matrix \\
40-2, 14-17, 1B & 0.10 & 33 & 180 & 41 & 180 & Fragments in clay matrix \\
41-2, 22-25 & 4.24 & -24 & 76 & -22 & 75 & Several clasts in clay matrix \\
41-2, 29-32 & 9.63 & -27 & -80 & -28 & -78 & Single clast \\
\hline
\end{tabular}


tion of the basalt was achieved. High $J_{N R M}$ values and the correct sense of remanence direction imply that a $1-\mathrm{km}$ source layer is sufficient to account for the magnetic anomaly at the drilling sites.

4) The igneous columns of Holes 417D and 418A consist of several segments of distinct stable inclination; within each segment the stable inclinations exhibit relatively small dispersion. This suggests an episodic origin for the igneous oceanic crust, where extrusive edifices of the order of 200-meter thickness can be produced in a relatively short period; that is, less than about 200 to 300 years.

5) The presence in Hole $418 \mathrm{~A}$ of stable-inclination sections representing both polarities of the Earth's magnetic field is evidence that the total period represented by the igneous column of this hole is at least several thousand years.

6) The average stable inclination of Holes 417D and $418 \mathrm{~A}$ is $41^{\circ}\left(\mathrm{S} . \mathrm{D} .=17^{\circ}\right)$ - steeper than, but not significantly different from, $32^{\circ}$ which is the inferred Cretaceous paleoinclination for the drilling sites.

7) Differences in the downhole profiles of the magnetic properties in Holes 417D and 418A suggest that particlesize variations of the magnetic minerals exercise important control on these properties, which might contribute to certain short-scale fluctuations in the magnetic signal observed at the sea surface.

8) The more substantial zones of brecciation of Holes 417D and 418A have no coherent remanence directions and make no net contribution to the magnetic layer that contains them. This suggests that brecciation occurred at temperatures below $200^{\circ} \mathrm{C}$.

\section{ACKNOWLEDGMENTS}

In particular, I thank Stan White for making many paleomagnetic measurements on the Glomar Challenger during Leg 52. C. G. A. Harrison, H. P. Johnson, R. T. Merrill, and R. Karlin offered helpful suggestions and criticisms. D. Schultz assisted with the laboratory measurements. This research was funded by the National Science Foundation's Oceanography section (OCE76-15255).

\section{REFERENCES}

Ade-Hall, J. M., Aumento, F., Brooke, J., McKeown, D. L., Ryall, P. J. C., and Gerstein, R. E., 1973. The mid-Atlantic ridge near $45^{\circ} \mathrm{N}, 12$, Magnetic results from basalt drill cores from the median valley, Can. J. Earth Sci., v. 10, p. 679-696.

Atwater, T. and Mudie, J. D., 1973. Detailed nearbottom geophysical study of the Gorda Rise, J. Geophys. Res., v. 78, p. $8665-8686$.

Ballard, R. D. and van Andel, T. H., 1977. Morphology and tectonics of the inner rift valley of lat. $36^{\circ} 50^{\prime} \mathrm{N}$ on the MidAtlantic Ridge, Geol. Soc. of Am. Bull., v. 88, p. 507-530.

Brooke, J., Irving, E., and Park, J. K., 1970. The mid-Atlantic ridge at $45^{\circ} \mathrm{N}, 13$, Magnetic properties of basalt bore-core, Can. J. Earth Sci., v. 7, p. 1515-1527.

Carle, M., 1976. Spreading rate as inferred from spacing of magnetic lineations. In Hoskins, H. and Groman, R. C., Informal report of surveys and IPOD sites AT2.2 and AT2.3, Woods Hole Oceanographic Institution, Woods Hole, p. 17-18.

Carmichael, C. M., 1970. The mid-Atlantic ridge near $45^{\circ} \mathrm{N}, 7$, Magnetic properties and opaque mineralogy of dredged samples, Can. J. Earth Sci., v. 7, p. 239-256.
Cox, A., 1970. Latitude dependence of the angular dispersion of the geomagnetic field, Geophys. J. Roy. Astron. Soc., v. 20, p. 253-269.

Cox, A. and Doell, R. R., 1962. Magnetic properties of the basalt in hole EM7, Mohole Project, J. Geophys. Res., v. 67, p. 3997-4004.

Creer, K. M., 1962. The dispersion of the geomagnetic field due to secular variation and its determination for remote times from paleomagnetic data, J. Geophys. Res., v. 67, p. 3461.

Faller, A. M., Steiner, M., and Kobayashi, K., 1979. Paleomagnetic results from basalts and interlayered sediments drilled during DSDP Leg 49, Initial reports of the Deep Sea Drilling Project, v. 49: Washington (U.S. Government Printing Office), p. 769-780.

Fisher, R. A., 1953. Dispersion on a sphere, Proc. Roy. Soc. Ser. A., v. 217 , p. $295-305$.

Harrison, C. G. A., 1976. Magnetization of the oceanic crust, Geophys. J.R. A.S., v. 47 , p. 257-284.

Harrison, C. G. A. and Somayajulu, B. L. K., 1966. Behavior of the Earth's magnetic field during a reversal, Nature, v. 212, p. 1193-1195.

Harrison, C. G. A. and Watkins, N. D., 1977. Shallow inclinations of remanent magnetism in Deep-Sea Drilling Project igneous cores: geomagnetic field behavior or postemplacement effects, J. Geophys. Res., v. 82, p. 4869-4877.

Irving, E. and Pullaiah, G., 1976. Reversals of the geomagnetic field, magnetostratigraphy, and relative magnitude of paleosecular variation in the Phanerozoic, Earth-Sci.Revs., v. 12, p. 35-64.

Irving, E., Robertson, W. A., and Aumento, F., 1970. The midAtlantic Ridge near $45^{\circ} \mathrm{N}, 6$, remanent intensity, susceptibility and iron content of dredged samples, Can. J. Earth Sci., v. 7, p. 226-238.

Johnson, H. P., 1979. Paleomagnetism of igneous rock samples - DSDP Leg 45. In Melson, W. G., Rabinowitz, P. D., et al., Initial Reports of the Deep Sea Drilling Project, v. 45: Washington (U.S. Government Printing Office), p. 387-396.

Johnson, H. P., and Atwater, T., 1977. A magnetic study of the basalts from the Mid-Atlantic Ridge at $37^{\circ} \mathrm{N}$, Bull. G.S.A., v. 88 , p. $637-642$.

, 1978. A detailed rock magnetic and opaque mineralogy study of the basalts from the Nazca Plate, Geophys. J. R.A.S., v. 52 , p. $45-64$.

Johnson, H. P. and Merrill, R. T., 1978. A direct test of the Vine-Matthews hyopthesis, Earth Planet. Sci. Lett., v. 40, p. 263-269.

Klitgord, K. D., Heustis, S. P., Mudie, J. D., and Parker, R. L., 1975. An analysis of near-bottom magnetic anomalies: seafloor spreading and the magnetized layer, Geophys. J.R.A.S., v. 43 , p. $387-424$

Levi, S. and Merrill, R. T., 1978. Properties of single domain, pseudosingle domain and multidomain magnetite, J. Geophys. Res., v. 83, p. 309-323.

Lowrie, W., 1973. Viscous remanent magnetization in oceanic basalts, Nature, v. 243 , p. 27-30.

, 1977. Intensity and direction of magnetization in oceanic basalts, J. Geol. Soc. London, v. 133, p. 61-82.

Lowrie, W., and Opdyke, N. D., 1972. Palemagnetism of igneous samples. In Hayes, D. E., Pimm, A. C., et al., Initial Reports of the Deep Sea Drilling Project, v. 14: Washington (U.S. Government Printing Office), p. 777-784.

, 1973. Paleomagnetism of igneous and sedimentary samples, Initial Reports of the Deep Sea Drilling Project, v. 15 , p. $1017-1022$.

Mankinen, E. A., 1978. Paleomagnetic evidence for a late Cretaceous deformation of the Great Valley sequence, Sacramento, California, J. Res. U.S.G.S., v. 6, p. 383-390. 
Marshall, M., 1978. The magnetic properties of some DSDP basalts from the north Pacific and inferences for Pacific plate tectonics, J. Geophys. R., v. 83, p. 289-308.

McElhinny, M. W. and Merrill, R. T., 1975. Geomagnetic secular variation over the past 5 .my., Revs. Geophys. Space Phys., v. 13 , p. $687-708$.

Opdyke, N. D., Kent, D. V., and Lowrie, W., 1973. Details of magnetic polarity transitions recorded in a high deposition rate deep-sea core, Earth Planet. Sci. Lett., v. 20, p. 315-324.

Peirce, J. W., 1976. Assessing the reliability of DSDP paleolatitudes, J. Geophys. Res., v. 81, p. 4173-4187.

Petersen, N., 1979. Rock and paleomagnetism of basalts from Site 396B, Leg 46. In Dmitriev, L., Heirtzler, J., et al., Initial Reports of the Deep Sea Drilling Project, v. 46: Washington (U.S. Government Printing Office), p. 357-362.

Prévot, M., Lecaille, A., Francheteau, J., and Hekinian, R., 1976. Magnetic inclination of basaltic lavas from the midAtlantic ridge near $37^{\circ} \mathrm{N}$, Nature, v. 259 , p. $649-653$.

Rietman, J. D., 1966. Remanent magnetization of late Yakima Basalt, Washington State, Ph.D. dissertation, Stanford University, 88 pages.

Ryall, P. J. C., Hall, J. M., Clark, J., and Milligan, T., 1977. Magnetization of oceanic crustal layer 2: results and thoughts after DSDP Leg 37, Can. J. Earth Sci., v. 14, p. 684-706.

Schouten, H., 1976. Paleolatitudes and synthetic anomaly pattern of $M 0$ DSDP sites proposed in the western north Atlantic. In Hoskins, H. and Groman, R. C. (Eds.), Informal report of surveys at IPOD sites AT2.2 and AT2.3, Woods Hole Oceanographic Institution, Woods Hole, Appendix 2.

Scientific Party, DSDP Leg 37, 1975. Sources of magnetic anomalies of the mid-Atlantic Ridge, Nature, v. 255, p. $389-$ 390.

Steiner, M., Day, R., Kobayashi, K., and Faller, A., 1979. Summary of magnetic observations of Leg 49, In Luyendyk, B., Cann, J. R., et al., Initial Reports of the Deep Sea Drilling Project, v. 49: Washington (U.S. Government Printing Office), p. 807-812.

Talwani, M., Windisch, C. C., and Langseth, M. G., Jr., 1971. Reykjanes ridge crest: a detailed geophysical study, $J$. Geophys. Res., v. 76, p. 473-517.
Watkins, N. D., and Baksi, A. K., 1974. Magnetostratigraphy and oroclinal folding of the Columbia River, Stiens, and Owyhee basalts in Oregon, Washington and Idaho, Am. J.Sci., v. 274 , p. $148-189$.

Wilson, R. L., Dagley, P., and McCormack, A. G., 1972. Paleomagnetic evidence about the source of the geomagnetic field, Geophys. J. R. A. S., v. 28, p. 213-224.

\section{APPENDIX \\ Exclusion of Samples From Analysis}

Samples for which no stable direction could be determined were excluded from the analysis of stable inclinations. Because of suspected misorientation, I also excluded two additional specimens from each hole from the analyses of the remanence directions, despite exhibiting stable directions. Samples 417D-52-5, 24-26 cm and 417D-54-3, 92-94 cm, as well as 418A-16-3, 64-67 cm and 418A-16-3, $83 \mathrm{~cm}$ were omitted from the analyses, because their ISTABLE is of opposite sign but similar absolute value as that of neighboring samples, either within the same core (in the case of Hole 417D) or in an adjacent core (as for Hole 418A). Furthermore, there are no lithological boundaries setting off the specimens with the anomalous inclinations, nor any other geological evidence to suggest a boundary or hiatus in the volcanism. Denser sampling is needed at these regions of anomalous inclinations to determine their extend and possible cause. At present, it seems that accidental mishandling rather than a "geomagnetic burp" is a more likely source for these inverted inclinations.

An anomalous inclination in a specimen studied onboard the Glomar Challenger (Sample 418A, 44-2, 99-102 cm) has led to extensive sampling for shore-based studies of this and neighboring sections of the core to determine the cause of the anomalous inclination. I discovered that the anomalous inclinations were confined to a single GRAPE section. ${ }^{1}$ In this case also it seems that the simplest explanation for these reversed inclinations in Core 44 is an accidental end-over-end rotation of the GRAPE section in question. The specimens of this "rotated" section were included in the analyses of this report, but signs of the inclination were inverted.

${ }^{1}$ Note that GRAPEing is done prior to inserting spacers between individual rocks; thus, each GRAPE section $(150 \mathrm{~cm})$ contains more rock than a final section. Correspondingly, the rocks of a GRAPE section usually end up occupying somewhat more than a single $150-\mathrm{cm}$ section. 